\title{
Quantitative assessment of Fibroblast Growth Factor Receptor 1 expression in neurons and glia
}

\author{
Lisha Choubey $^{1}{ }^{\text {, Jantzen C Collette }}{ }^{1}$, Karen Müller Smith ${ }^{\text {Corresp. } 1}$ \\ ${ }^{1}$ Department of Biology, University of Louisiana at Lafayette, Lafayette, LA, United States of America \\ Corresponding Author: Karen Müller Smith \\ Email address: karenmsmith@gmail.com
}

Background. Fibroblast growth factors (FGFs) and their receptors (FGFRs) have numerous functions in the developing and adult CNS. For example, the FGFR1 receptor is important for proliferation and fate specification of radial glial cells in the cortex and hippocampus, oligodendrocyte proliferation and regeneration, midline glia morphology and soma translocation, Bergmann glia morphology, and cerebellar morphogenesis. In addition, FGFR1 signaling in astrocytes is required for postnatal maturation of interneurons expressing parvalbumin (PV). FGFR1 is implicated in synapse formation in the hippocampus, and alterations in the expression of Fgfr1 and its ligand, Fgf2 accompany major depression. Understanding which cell types express Fgfr 1 during development may elucidate its roles in normal development of the brain as well as illuminate possible causes of certain neuropsychiatric disorders.

Methods. Here, we used a BAC transgenic reporter line to trace Fgfrl expression in the developing postnatal murine CNS. The specific transgenic line employed was created by the GENSAT project, tgFGFR1-EGFPGP338Gsat, and includes a gene encoding enhanced green fluorescent protein (EGFP) under the regulation of the Fgfr 1 promoter, to trace Fgfr 1 expression in the developing CNS. Unbiased stereological counts were performed for several cell types in the cortex and hippocampus.

Results. This model reveals that Fgfr 1 is primarily expressed in glial cells, in both astrocytes and oligodendrocytes, along with some neurons. Dual labeling experiments indicate that the proportion of GFP+ (Fgfr $1+)$ cells that are also GFAP+ increases from postnatal day 7 (P7) to 1 month, illuminating dynamic changes in Fgfrl expression during postnatal development of the cortex. In postnatal neurogenic areas, GFP expression was also observed in SOX2, doublecortin (DCX), and brain lipid-binding protein (BLBP) expressing cells. Fgfrl is also highly expressed in DCX positive cells of the dentate gyrus (DG), but not in the rostral migratory stream. Fgfrl driven GFP was also observed in tanycytes and GFAP+ cells of the hypothalamus, as well as in Bergmann glia and astrocytes of the cerebellum.

Conclusions. The tgFGFR1-EGFPGP338Gsat mouse model expresses GFP that is congruent with known functions of FGFR1, including hippocampal development, glial cell development, and stem cell proliferation. Understanding which cell types express Fgfr1 may elucidate its role in neuropsychiatric disorders and brain development. 
1 Quantitative assessment of Fibroblast Growth Factor Receptor 1 expression in Neurons and

2 Glia

3 Short title: $F g f r l$ expression in Neurons and Glia

4 Lisha Choubey ${ }^{1}$, Jantzen Collette ${ }^{1}$, Karen Müller Smith ${ }^{1 *}$

5 1. Department of Biology, University of Louisiana at Lafayette, Lafayette, LA, USA

6 *Corresponding author

7 Email: karen.smith@,louisiana.edu (KMS)

8 Running head: $\quad F g f r l$ is expressed in neurons and glia

\section{Abstract}

10 Background. Fibroblast growth factors (FGFs) and their receptors (FGFRs) have numerous

11 functions in the developing and adult CNS. For example, the FGFR1 receptor is important for

12 proliferation and fate specification of radial glial cells in the cortex and hippocampus,

13 oligodendrocyte proliferation and regeneration, midline glia morphology and soma translocation,

14 Bergmann glia morphology, and cerebellar morphogenesis. In addition, FGFR1 signaling in

15 astrocytes is required for postnatal maturation of interneurons expressing parvalbumin (PV).

16 FGFR1 is implicated in synapse formation in the hippocampus, and alterations in the expression

17 of Fgfrl and its ligand, Fgf2 accompany major depression. Understanding which cell types

18 express $F g f r l$ during development may elucidate its roles in normal development of the brain as

19 well as illuminate possible causes of certain neuropsychiatric disorders. 
20 Methods. Here, we used a BAC transgenic reporter line to trace Fgfrl expression in the

21 developing postnatal murine CNS. The specific transgenic line employed was created by the 22 GENSAT project, tgFGFR1-EGFPGP338Gsat, and includes a gene encoding enhanced green

23 fluorescent protein $(E G F P)$ under the regulation of the $F g f r 1$ promoter, to trace $F g f r l$ expression

24 in the developing CNS. Unbiased stereological counts were performed for several cell types in 25 the cortex and hippocampus.

26 Results. This model reveals that Fgfrl is primarily expressed in glial cells, in both astrocytes and

27 oligodendrocytes, along with some neurons. Dual labeling experiments indicate that the

28 proportion of GFP $+(F g f r l+)$ cells that are also GFAP+ increases from postnatal day $7(\mathrm{P} 7)$ to 1

29 month, illuminating dynamic changes in Fgfrl expression during postnatal development of the

30 cortex. In postnatal neurogenic areas, GFP expression was also observed in SOX2, doublecortin

31 (DCX), and brain lipid-binding protein (BLBP) expressing cells. Fgfrl is also highly expressed in

32 DCX positive cells of the dentate gyrus (DG), but not in the rostral migratory stream. Fgfrl

33 driven GFP was also observed in tanycytes and GFAP+ cells of the hypothalamus, as well as in

34 Bergmann glia and astrocytes of the cerebellum.

35 Conclusions. The $\operatorname{tg} F G F R 1-E G F P G P 338$ Gsat mouse model expresses GFP that is congruent

36 with known functions of FGFR1, including hippocampal development, glial cell development,

37 and stem cell proliferation. Understanding which cell types express $F g f r l$ may elucidate its role

38 in neuropsychiatric disorders and brain development.

\section{Introduction}

40 Differential binding of FGFs to FGF receptor isoforms may confer a high degree of

41 selectivity leading to signaling events that lead to a multitude of specific cellular responses

42 (Chellaiah et al., 1999, Iwata and Hevner, 2009, Hebert, 2011, Ornitz and Itoh, 2015). Multiple

43 Fgf ligands and three of the Fgfrs (Fgfr1, Fgfr2, and Fgfr3) are expressed in the CNS during

44 development, in postnatal stem cell niches such as the dorsal VZ, and in glial lineages (el- 
45 Husseini et al., 1994, Belluardo et al., 1997, Bansal et al., 2003, Cahoy et al., 2008, Doyle et al., 46 2008, Garcia-Gonzalez et al., 2010, Azim et al., 2012). This complex system of Fgfs and Fgfrs 47 plays a pivotal role in the normal development, maturation, and function of the central nervous 48 system (CNS) (Iwata and Hevner, 2009, Stevens et al., 2010b, Hebert, 2011). FGF signaling is 49 implicated in patterning of the CNS, in determining neuronal and glial cell fate, in influencing 50 cerebral cortex size through maintenance of radial glial stem cells, in cerebellar development, and 51 in regional patterning of the neocortex and midbrain-hindbrain boundaries (Vaccarino et al., 52 1999, Fukuchi-Shimogori and Grove, 2001, Korada et al., 2002, Storm et al., 2003, Shin et al., 53 2004, Gutin et al., 2006, Smith et al., 2006, Storm et al., 2006, Cholfin and Rubenstein, 2007, 54 Muller Smith et al., 2008, Kang et al., 2009, Stevens et al., 2010a, Rash et al., 2011, Muller Smith 55 et al., 2012, Rash et al., 2013, Kang et al., 2014, Smith et al., 2014).

56 Loss of FGFR1 function by $h G F A P-C r e$-induced deletion of Fgfr $1^{\text {floxflox }}$ alleles in the

57 dorsal telencephalon of mice results in decreased hippocampal size and volume, with a reduction

58 in the number of dividing progenitor cells of the ventricular zone and DG (Ohkubo et al., 2004).

59 Fgfrl mutants also exhibit a disruption in corpus callosum and hippocampal commissure due to 60 abnormal midline glia development (Smith et al., 2006, Tole et al., 2006). The midline glial cells 61 fail to undergo soma translocation and formation of the indusium griseum leading to midline 62 commissural axon guidance defects (Smith et al., 2006). Furthermore, these mice exhibit

63 postnatal loss of maturation in GABAergic interneurons expressing parvalbumin (PV) and exhibit 64 behavioral hyperactivity (Muller Smith et al., 2008, Smith et al., 2014). Hyperactivity and a 65 decrease in number of interneurons in the cortex co-occur in patients with schizophrenia (Volk et 66 al., 2000, Akbarian and Huang, 2006, Hashimoto et al., 2008, Volk and Lewis, 2013).

67 Interestingly, Fgfrl expression was found to be increased in the prefrontal cortex of individuals 68 with schizophrenia (Volk et al., 2016). Dual inactivation of floxed alleles of Fgfrl and Fgfr2 69 results in abnormal cerebellar morphogenesis including reduced size of the cerebellum due to a 
70 defect in proliferation of both cerebellar glia and granule cell precursors, abnormal orientation

71 and morphology of Bergmann glia, and loss of laminar architecture (Muller Smith et al., 2012).

72 This phenotype is similar to that observed in Fgf9 mutants (Lin et al., 2009). FGFRs are

73 implicated in maintaining astrocytes in a non-reactive state, and in impeding glial scar formation

74 (Kang et al., 2014). When Fgfrl deletions were targeted to oligodendrocyte lineages, they did not

75 disrupt oligodendrocyte birth, but modulated myelin sheath thickness and remyelination in

76 chronic demyelination models (Furusho et al., 2012, Furusho et al., 2015). Administration of

77 FGF2 into the lateral ventricles has also been shown to increase the number of oligodendrocyte

78 precursor cells in the SVZ (Azim et al., 2012).

79 Patients with major depressive disorder (MDD) and bipolar disorder have altered gene

80 expression of FGFs and FGFRs (Evans et al., 2004, Gaughran et al., 2006). In situ hybridization

81 revealed that mRNA for $F g f r l$, and its ligand $F g f 2$, were both down regulated in the hippocampus

82 of rats that had undergone the social defeat paradigm (Turner et al., 2008). Microinjections of

83 FGF2 into the lateral ventricles of rats resulted in an increase in Fgfrl mRNA in the DG within

8424 hours post FGF2 injections and was accompanied by acute antidepressant-like effects in the

85 force swim test (Elsayed et al., 2012). Furthermore, increased anxiety, dysregulation of the

86 hypothalamic pituitary axis and decreased hippocampal glucocorticoid receptor expression is

87 observed in FGF2 knockout mice. These effects are reversible by administration of FGF2

88 (Salmaso et al., 2016). FGF22 and FGF7 are presynaptic organizing molecules that promote

89 differentiation of excitatory and inhibitory presynaptic terminals in the hippocampal cornu

90 ammonis (CA) region 3 through combinatorial signaling of sets of FGFRs (Umemori et al., 2004,

91 Terauchi et al., 2010, Dabrowski et al., 2015). Given the data that FGF2/FGFR1 signaling is

92 important for the regulation of mood and affect, and that FGFR1 signaling may participate in

93 synaptogenesis, a better understanding of the cell types expressing $F g f r l$ is important to

94 improving our understanding of its actions. 
96 studies and from immunochemistry using antibodies against FGFR1 (Gonzalez et al., 1995,

97 Belluardo et al., 1997, Bansal et al., 2003, Ohkubo et al., 2004, Blak et al., 2005), while more

98 recently, molecular studies have identified the timing and or cell specific expression of Fgfr 1

99 (Doyle et al., 2008, Garcia-Gonzalez et al., 2010, Azim et al., 2012). In embryonic mice, Fgfrl is

100 strongly expressed in the hippocampal hem, choroid plexus, cortical ventricular zone, and cortical

101 midline (el-Husseini et al., 1994, Bansal et al., 2003, Ohkubo et al., 2004, Smith et al., 2006). In

102 adult mice, the strongest Fgfrl expression is observed in the hippocampus (Ohkubo et al., 2004).

103 Based on a literature review, Turner and colleagues surmised that neuronal populations in the

104 adult hippocampus and cortex mostly express Fgfrl, in contrast to other FGF receptors that are

105 considered to be expressed primarily in glia (Turner et al., 2012a).

106 Despite clear advances in our understanding of FGF signaling derived from in situ

107 hybridization, it suffers from poor cell-type resolution. Likewise, although immunocytochemistry

108 using antibodies raised to FGFR1 has proven to be important, cross-reactivity to other FGFRs

109 remains a concern. To circumvent these issues, we investigated Fgfrl expression in PV+

110 interneurons, employing a transgenic reporter line, $\operatorname{tg} F G F R 1-E G F P G P 338 G s a t$ bacterial

111 artificial chromosome (BAC), that was obtained from GENSAT, http://www.gensat.org (Smith et

112 al., 2014). In this transgenic line, the gene encoding enhanced green fluorescent protein (EGFP)

113 is regulated under the same promoter as Fgfrl. Thus, GFP fluorescence should indicate

114 expression of genes encoding Fgfrl. We previously showed that in $\operatorname{tgFGFR1-EGFPGP338Gsat}$

115 mice, PV+ interneurons did not colocalize with GFP+ cells. Thus, the decrease in PV+

116 interneurons due to inactivation of Fgfrl occurs non-cell-autonomously (Smith et al., 2014). We

117 also observed that a large number of glia appeared to express $F g f r l$ in adult mice. In the present

118 study, we extend our studies and present a quantitative analysis of the relative expression of

119 Fgfrl in neurons versus glial cells during postnatal development of the telencephalon. We show 
120 that Fgfrl is differentially expressed, primarily in GFAP+ astrocytes and OLIG2+ cells, with a

121 minority of cells colocalizing with NeuN+ neurons. Furthermore, SOX2+ cells, BLBP + cells and

122 DCX + cells in the cortex, hippocampus, subventricular zone (SVZ), and hypothalamus of mice

123 are colocalized with the GFP signal, indicating that these cells also express Fgfrl.

124 Methods and Materials

125 Animals

126 Wild type Swiss Webster mice were crossed with mice expressing enhanced green

127 fluorescent protein (EGFP) under the same promoter as Fgfrl (tgFGR1-EGFPGP338Gsat). The

128 transgenic line, $\operatorname{tg} F G R 1-E G F P G P 338 G$ sat was generated from the GENSAT project

129 (GENSAT.org) by microinjecting bacterial artificial chromosome with Fgfrl promoter driving

130 EGFP into the pronucleus of fertilized mouse eggs. GENSAT produces transgenic BAC-EGFP

131 reporter and BAC-Cre recombinase driver mouse lines with the aim to map the expression of

132 genes in the CNS of mice (Heintz, 2004). This line was obtained from the Mutant Mouse

133 Resource Center (MMRRC.org) at UC Davis. This study was conducted in an ethical manner,

134 utilizing the recommendations of The Guide for the Care and Use of Laboratory Animals of the

135 National Institutes of Health. Animals were euthanized under the University of Louisiana at

136 Lafayette IACUC committee APS numbers 2012-8717-046, 2013- 8717-053, 2014-8717 040,

137 2015-8717-033. Tissue collected for this study was performed under ketamine/xylazine cocktail

138 for P7 and older animals.

139 Genotyping

140 The mice were genotyped by polymerase chain reaction (PCR) for GFP and through GFP

141 screening with goggles containing a GFP filter (BLS LTD). For PCR based genotyping, tails of

142 mice were collected and DNA was extracted from the tail using $50 \mathrm{mM}$ sodium hydroxide $\left(95^{\circ} \mathrm{C}\right.$

143 for $30 \mathrm{~min}$ ), followed by neutralization with 1M TRIS ( $\mathrm{pH} 7.6$ ). Master mix for 1 reaction of

144 PCR for amplifying GFP was created using $2.5 \mu$ of 10x PCR buffer, $0.5 \mu 1$ of $10 \mathrm{mM}$ dNTP mix,

$1451 \mu \mathrm{l}$ of eGFP forward and reverse primer mix (Forward: AAGTTCATCTGCACCACCG and 
146 Reverse: TGCTCAGGTAGTGGTTGTCG), $0.2 \mu \mathrm{l}$ of 5 units/ $\mu 1$ Hot start Taq Polymerase and

$14718.8 \mu \mathrm{l}$ of distilled water. Two microliters of DNA sample were added to $23 \mu \mathrm{l}$ of Master mix per

148 PCR tube and the samples were amplified in the Applied Biosystems 96 Well Thermocycler. In

149 adult $\operatorname{tgFGR} 1-E G F P G P 338 G$ sat positive mice, we found we could reliably genotype mice due to

150 GFP expression in the eye, using GFP goggles (available from BLS).

151 Immunostaining

152 P7 mice were anesthetized with ketamine/xylazine (100 mg and10mg per $\mathrm{kg}$ of body

153 weight respectively) and euthanized by cervical dislocation. Brains were dissected out and in $4 \%$

154 PFA overnight. Adult mice were euthanized by cardiac perfusion under deep anesthesia

155 (ketamine/xylazine as above). Mice were perfused with cold 1x Phosphate Buffered Saline (PBS)

156 followed by 4\% PFA in 1x PBS. Brains were post fixed overnight and cryoprotected as described

157 above. Brains collected from P7 and one month ages were cryoprotected in $20 \%$ sucrose/1xPBS,

158 and cryopreserved with exposure to dry ice and embedded in optimal cutting temperature (OCT)

159 at the time of sectioning. The tissue was thick sectioned ( $50 \mu \mathrm{m}$, free floating) in a cryostat

160 (Microm, HM 505 E) in a series of 10 vials containing 1xPBS. Samples were stored in PBS with

$1610.2 \%$ sodium azide at $4^{\circ} \mathrm{C}$, and protected from light exposure.

162 Prior to antibody incubation, sections were blocked with $10 \%$ serum in PBS with $0.2 \%$

163 triton x (Sigma Aldrich) and 0.1\% tween 20 (Sigma Aldrich), except for anti-Gad67 staining

164 which did not include detergents. Primary antibodies (Table 1) were detected with Alexa

165 conjugated secondary antibodies (Jackson labs and Abcam) or AMCA conjugated secondary

166 antibodies (Vector) in 5\% serum. VECTASHIELD DAPI used for double staining and

167 VECTASHIELD without DAPI used for triple staining when mounting sectioned tissue onto

168 polyprep slides.

169 Cell Counting

170 Unbiased estimated counts of astrocytes expressing glial fibrillary acidic protein (GFAP),

171 neurons expressing NeuN, and oligodendrocytes and oligodendrocyte precursors expressing

172 Olig2 were obtained using StereoInvestigator software (Microbrightfield, MBF) coupled with an 
173 AxioCam MRm on the Zeiss axioimager microscope equipped with an ApoTome.2. The Optical

174 Fractionator probe on Stereoinvestigator was employed, with tops of cells counted in three-

175 dimensional counting boxes, which were set to specific parameters (Table 2). For counts of the

176 cortex and hippocampus, $50 \mu \mathrm{m}$ sections were sampled every $20^{\text {th }}$ (cortex) and every $10^{\text {th }}$ section

177 (Hippocampus). The CA1, CA2, and CA3 regions were counted together and included the

178 stratum lacunosum, stratum radiatum, stratum pyramidale and the Stratum Oriens. The DG was

179 counted separately. For the cortex, at these ages, the expression of GFP seemed fairly ubiquitous

180 and so the cortex was counted in its entirety using stereology as outlined above and in Table 2.

181 Fluorescence images were acquired through StereoInvestigator imaging software. Of note, cell

182 counts indicated that presence of the GFP transgene did not cause cell lethality in cortical or

183 hippocampal cells. For P7 counts, 3 animals per genotype were counted for NeuN, GFAP, and

184 Olig2 (same animals for all 3 counts). For 1 month old animals, 3 animals per group were

185 counted for cortex and CA, and 4 animals in the GFP+ group for the DG. The GFAP/NeuN /GFP

186 counts were determined from triple stained samples. The Olig2 counts were from 3 animals per

187 group.

188 To determine the percentage of GFP+ cells that were neuronal stem cells expressing Sox 2

189 and neuroblasts expressing DCX (3 animals per group), we acquired $\mathrm{z}$ stack images of the

190 anterior DG hemisphere and a section $500 \mu \mathrm{m}$ posterior to this first section. The $\mathrm{z}$ stack images

191 obtained to count SOX2 markers were $19 \mu \mathrm{m}$ thick with each slice $1 \mu \mathrm{m}$ thick from $3 \mathrm{GFP}+$ mice

192 and 2 for the control mice). The $\mathrm{z}$ stack images acquired to count DCX markers were $10 \mu \mathrm{m}$ thick

193 with each slice $1 \mu \mathrm{m}$ thick (3 animals per group).

194 Statistical Analysis

195 Data from the StereoInvestigator software were entered into Excel, imported to JMP Pro 11, and

196 analyzed by student t-tests, or ANOVA, using SAS.

\section{Results}


198 Fgfr1 is expressed in various cells types of the dentate gyrus, CA, and subventricular zone

199 (SVZ) at P7

200 Previous in situ studies indicated high levels of Fgfrl mRNA in the hippocampus,

201 including DG and CA regions. To investigate the cell types expressing Fgfrl in the hippocampus

202 of P7 control and tgfgfr l-EGFP+ mice, samples were stained by immunocytochemistry for cell-

203 type markers to identify each of the following: GFAP+ stem cells and astrocytes, NeuN+

204 neurons, BLBP+ stem cells, and DCX+ neuroblasts. We also used an anti GFP antibody to ensure

205 detection of GFP in fixed tissue. However, Gfp expression is visible without amplification,

206 especially in the hippocampus and subventricular zone. The cell-type marker staining (red

207 fluorescence) was imaged alongside GFP immunostaining (green fluorescence) to reveal which

208 cell types express Fgfrl and with DAPI counterstaining (blue fluorescence) to image nuclei (Fig.

209 1). The colocalization of a cell type marker and $F g f r l$ expression is indicated by yellow

210 fluorescence caused by overlapping red and green fluorescence. GFAP and GFP immunostaining

211 showed GFP+ cells in the GFAP+ stem cells of the subgranular zone (SGZ) of the DG of $\operatorname{tg} f g f r l$ -

$212 E G F P+$ mice (Fig. 1A-C, Fig. S1, and https://figshare.com/s/36bc336d5b0ccb95efe8) with

213 little to no green fluorescence in GFP- controls (Fig. 1D-F). In the CA region of the

214 hippocampus, GFAP+/GFP+ cells were primarily observed surrounding the stratum pyramidale,

215 in the stratum radiatum, stratum oriens, as well as the white matter above the CA region (Fig. 1

216 G-I, Fig. S1) with little to no green fluorescence in GFP- littermate controls (Fig. 1 J-L). There

217 was strong GFP fluorescence in the stratum pyramidale of the CA region. This GFP staining

218 colocalized with NeuN+ cells (neurons) (Fig. 2A-C, Fig. S2) with little to no green fluorescence

219 in GFP- littermate controls (Fig. 2D-F). NeuN+/GFP+ cells were also observed in some, but not

220 all, granule cell layer neurons of the developing DG of $\operatorname{tg} f g f r 1-E G F P+$ mice (Fig. 2G-I) with

221 little to no green fluorescence in GFP- controls (Fig. 2J-L). Stereological analysis of tgfgfrl-

222 EGFP expression in GFAP+ cells of the DG showed that of GFP + cells, $24 \% \pm 8 \%$ are GFAP 
223 positive, and of GFAP + cells, $50 \% \pm 8 \%$ are GFP + . Of GFP + cells in the CA, 50\% $\pm 5 \%$ are

224 GFAP positive and of GFAP + cells in the CA, 43\% \pm 9\% are GFP positive (Table 3). One-way

225 ANOVA statistical analysis revealed that the total number of GFAP+ cells in the DG and CA of

226 tgfgfrl-EGFP+ are not significantly different from their littermate controls (Table 3).

227 We further explored Fgfrl promoter driven expression of Gfp in the postnatal neurogenic

228 niches of the DG and SVZ of the lateral ventricles at P7. Immunostaining for DCX (neuroblasts)

229 and GFP extensively colocalized in the SGZ and granule cell layer (GCL) of the DG (Fig. 3A and

230 3B, low and high magnification respectively) with nearly all DCX positive cells co-expressing

231 GFP. Postnatally, the SVZ of the lateral ventricles gives rise to olfactory bulb neurons, astrocytes

232 and oligodendrocytes (Chaker et al., 2016). The kind of olfactory bulb neuron generated depends

233 on the location of the stem cell within the VZ (Fiorelli et al., 2015, Chaker et al., 2016). GFP+

234 cells were observed in the SVZ, consistent with previous studies of postnatal Fgfrl expression

235 (Fagel et al., 2009). However, DCX did not colocalize with GFP staining in the SVZ of the lateral

236 ventricles (Fig. 3C), in contrast to what was observed in the DG of the hippocampus. This

237 difference is likely reflective of the differences in cell type generated, granule cell neurons that

238 are projection neurons in the SGZ and largely interneurons in the SVZ. Immunostaining with

239 BLBP (stem cells) and GFP antibodies revealed colocalization of Fgfr1 driven GFP in the

240 subgranular zone (SGZ) of the DG (Fig. 3D and 3E, low and high magnification, respectively) as

241 well as BLBP+ cells of the SVZ (Fig. 3F,G).

$242 \quad F g f r 1$ is expressed in cortical GFAP+ astrocytes and NeuN+ neurons at P7

243 To determine which cortical cells express Fgfrl, we stained the cortical tissue of P7

$244 \operatorname{tg} f g f r l-E G F P+$ and control mice with GFAP and NeuN antibodies. Whereas GFP+ cells

245 colocalized with GFAP+ astrocytes throughout the cortex (Fig. 4A-C), GFP+ cells colocalized

246 with NeuN+ cells (neurons) mostly in layers 5 and 6 of the cortex at this age (Fig. 4D-F).

247 Stereological analysis of the cortex region revealed that of GFP+ cells in the cortex, $32 \% \pm 4 \%$

248 are GFAP positive. Of the cortical GFAP + cells, $93 \% \pm 2 \%$ are GFP positive. This analysis 
249 indicates that most Gfap expressing astrocytes also express Fgfrl. The total number of cortical

250 GFAP + cells of $\operatorname{tg} f g f r 1-E G F P+$ mice was not significantly different from the number of cells in

251 littermate controls (Table 3), suggesting that the insertion of the transgene does not significantly

252 alter the number of astrocytes expressing Gfap.

253 We examined whether tgfgfrl-EGFP+ was expressed in oligodendrocytes and their

254 precursors by staining for OLIG2 in the cortex. We found that OLIG2+ staining colocalized with

255 GFP in the cortex (Fig. 4G-I). We also found sparse colabeling of OLIG2+ cells in the SVZ and

256 subcortical white matter (Fig. 4J). GFP expression within these cells appears to be lower than

257 that of surrounding cells, and may reflect residual GFP expression once progenitor cells that

258 express Fgfrl have divided and an oligodendrocyte has initiated differentiation to a more mature

259 subtype. At P7, radial glia of the cortex are undergoing soma translocation to become astrocytes,

260 and can be detected with BLBP. BLBP and GFP immunostaining revealed strong colocalization

261 throughout the cortex (Fig. 4K-M). At P7, GFP staining colocalized with BLBP+ stem cells and

262 Bergmann Glia in the developing cerebellum (Fig. 4N). This finding is consistent with the

263 participation of FGFR1/FGFR2 signaling in Bergmann Glia morphology and cerebellar

264 development (Muller Smith et al., 2012). Furthermore, GFP+ cells colocalized with GFAP+

265 astrocytes of the cerebellum, but not within granule cell layer or molecular layer neurons that

266 stain with NeuN. GFP+ cells likely colocalized with NeuN- Purkinje neurons based on the

267 location and size of GFP+ cells in the Purkinje layer (Fig. S3 and

268 https://figshare.com/s/722ecee87a3f32427759). While counts were not obtained from regions

269 such as the striatum or the thalamus, we observed GFAP colocalization with GFP in multiple

270 areas of the brain, and this seemed to be a general feature of GFAP positive cells.

271 Fgfrl is expressed in specific cell types of the hippocampus and SVZ at 1 month

272 We next investigated Fgfrl expression in 1-month $\operatorname{tg} f g f r l-E G F P+$ mice. Immunostaining

273 for SOX2 + cells (stem cells), $\mathrm{DCX}+$ cells (neuroblasts), NeuN+ neurons, GFAP+ astrocytes and

274 stem cells, and OLIG2+ oligodendrocytes was performed in combination with GFP 
275 immunostaining to determine which cell types express Fgfrl in the DG and CA of the

276 hippocampus, as well as the SVZ. GFP+ cells colocalized with SOX2+ cells (Fig. 5A-E, Fig.

277 S4A,B) and DCX + cells (Fig. 5F-J, Fig. S4C,D) in the SGZ and granule cell layers. To

278 determine the percentage of GFP+ cells that were SOX-2 positive and DCX positive, we obtained

279 z stack images of an anterior dentate gyrus hemisphere and posterior dentate gyrus hemisphere,

280 and performed counts from these images. Of the GFP+ cells counted in the $\mathrm{z}$ stack, $33 \% \pm 2 \%$ are

281 SOX2 positive. Conversely, the majority of SOX $2+$ cells, $71 \% \pm 2 \%$, are GFP positive (Fig. 5E).

282 Of the GFP + cells counted in the $\mathrm{z}$ stack, $64 \% \pm 0.9 \%$ are DCX positive and of DCX + cells, $86 \%$

$283 \pm 2 \%$ are GFP positive (Fig. 5J). Triple staining with GFP, GFAP and NeuN antibodies revealed

284 that GFAP+ cells (stem cells) and NeuN+ cells (neurons) colocalized with GFP+ cells in the SGZ

285 (Fig. 5K-N, Fig. S4E) and in the CA region (Fig. 5O-R, , Fig. S4F), respectively. GFP+ cells did

286 not colocalize with OLIG2+ cells (oligodendrocytes) in the DG (Fig. S5). Taken together, these

287 results indicate that GFP $(F g f r l)$ was expressed in stem cells and neuroblasts of the DG.

288 Stereological analysis of $\operatorname{tg} f g f r l-E G F P$ expression in NeuN+ cells of the DG showed that of

$289 \mathrm{GFP}+$ cells, $16 \% \pm 6 \%$ are NeuN positive and of $\mathrm{NeuN}+$ cells, $5 \% \pm 0.7 \%$ are GFP positive. Of

$290 \mathrm{GFP}+$ cells in the CA, $25 \% \pm 7 \%$ are NeuN positive and of $\mathrm{NeuN}+$ cells, $15 \% \pm 6 \%$ are GFP

291 positive. Stereological analysis of tgfgfrl-EGFP expression in GFAP+ cells of the DG showed

292 that of GFP + cells, $51 \% \pm 3 \%$ are GFAP positive and of GFAP + cells, $85 \% \pm 4 \%$ are GFP

293 positive. Of GFP+ cells in the CA, 61\% $\pm 9 \%$ are GFAP positive and of GFAP + cells, $81 \% \pm 3 \%$

294 are GFP positive. These findings indicate that most GFAP positive astrocytes express $F g f r 1$ at 1

295 month. The total number of SOX2+ cells, DCX + cells, NeuN+ cells and GFAP+ cells of $\operatorname{tg} f g f r 1-$

$296 E G F P+$ mice were not significantly different from their littermate controls in the DG and CA

297 (Sox2: $\mathrm{p}=0.23$, DCX: $\mathrm{p}=0.88$ and Table 3).

298 Many GFAP+ cells also express GFP in the SVZ (Fig. 6A-H) of 1 month tgfgfrl-EGFP+

299 mice. Colocalized GFP positive cells and GFAP positive fibers were observed both within the 
300 SVZ and in the white matter above it (Fig. 6D,G,H). There was also significant colocalization of

301 GFP with SOX2+ cells (Fig. 6I-L) indicating that GFAP+ and SOX2+ stem cells of the SVZ

302 express Fgfrl. Similar to what was found at P7, GFP+ cells did not colocalize with DCX+ cells

303 (neuroblasts) in the SVZ (Fig. 6M-O) or in the DCX + cells of rostral migratory stream (RMS) as

304 it enters the olfactory bulb (Fig. 6P). In the rostral migratory stream, GFP staining surrounds the

305 DCX + cells as would be expected from astrocytes surrounding the migrating neuroblasts.

306 Fgfr 1 is expressed in cortical GFAP+ astrocytes, NeuN+ neurons and OLIG2+ cells at 1

307 month

308 To determine which cortical cells express Fgfrl, we examined cortical tissue of 1-month

309 old tgfgfrl-EGFP+ and control mice immuonostained with GFAP, NeuN or OLIG2 antibodies

310 alongside GFP antibodies. Analysis of Fgfrl expression in the cortex revealed that GFP+ cells

311 colocalized with GFAP+ and NeuN+ cells (Fig. 7A-E, compared to control F). Of note, GFP

312 immunofluorescence appeared less brightly fluorescent in cells colocalizing with NeuN

313 compared to those colocalizing with GFAP. GFP+ cells also colocalized with OLIG2+ cells (Fig.

314 7G-H) with little to no green fluorescence occurring in littermate controls (Fig. 7I). Stereological 315 analysis of the cortex revealed that of GFP + cells, $57 \% \pm 7 \%$ are GFAP positive. Of the GFAP + 316 astrocytes, $83 \% \pm 6 \%$ are GFP positive. Of GFP + cells, $25 \% \pm 4 \%$ are NeuN positive and of $317 \mathrm{NeuN}+$ cells, $12 \% \pm 2 \%$ are GFP positive. Of GFP + cells, $29 \% \pm 0.9 \%$ are OLIG 2 positive and 318 of OLIG $2+$ cells, $58 \% \pm 0.08 \%$ are GFP positive. The total number of cortical GFAP + , NeuN + , 319 and OLIG2+ cells of $\operatorname{tg} f g f r 1-E G F P+$ mice were not significantly different from their littermate 320 controls (Table 3).

$321 \quad F g f r 1$ is expressed in various cell types of the hypothalamus at P7 and 1 month 322 Comparing Fgfrl expression in different regions of the P7 and 1-month old mice, we

323 observed GFP expression in cells of the hypothalamus and among cells lining the third ventricle,

324 within the arcuate nucleus and median eminence (Fig. 8, Fig. S6 and

325 https://figshare.com/s/f17d6889939bd680152d). Compared to the control hypothalamus (Fig. 
326 8A-C), GFP+ cells strongly colocalized with SOX2+ cells throughout the hypothalamus and third

327 ventricle and arcuate nucleus (Fig. 8D-I) in 1-month $\operatorname{tg} f g f r 1-E G F P+$ mice. GFAP+ tanycytes,

328 including those of the arcuate nucleus were among the hypothalamic cells observed to express

329 Fgfrl both at 1 month and at P7 (Fig. 8J-L). Tanycytes participate in neuroendocrine regulation

330 and transport of molecules from the CSF to the hypothalamus, release of gonadotropin-releasing

331 hormone, and production of triiodothyronine (T3) in the brain (Rodriguez et al., 2005). GFP

332 expression was not observed in $\mathrm{NeuN}+$ or OLIG2+ cells of the hypothalamus (Fig. 8M-O, Fig.

333 S6 A-D). At P7, we also observed colocalization of BLBP and GFP in the hypothalamus near the

334 third ventricle, but not many in the median eminence (Fig. S6 E,F,

335 https://figshare.com/s/f17d6889939bd680152d).

336 Calretinin (CR) and somatostatin (SST) neurons express Fgfrl in one-month old mice.

337 The NeuN+/GFP+ neurons observed at 1 month were not restricted to any specific

338 cortical layer, and a minority population of GFP colocalized with $\mathrm{NeuN}+$ neurons. We therefore

339 sought to determine if inhibitory neurons express $F g f r l$. Tissue from one-month old $\operatorname{tg} f g f r l$ -

$340 E G F P+$ mice (Fig. 9B-C) and their control littermates (Fig. 9A) was stained for GAD67. Some

341 GAD67+ cells colocalized with GFP in the cortex (Fig. 9B), but not in the hippocampus (Fig.

342 9C) or SVZ (Fig. 9D). Our previous investigations determined that GFP was not colocalized

343 with PV+ interneurons (Smith et al., 2014). This led to the experiments in which staining the one-

344 month old tissue with calretinin (CR) and somatostatin (SST) was performed alongside GFP

345 immunostaining. CR+ inhibitory neurons express GFP in the cortex (Fig. 9E, F), DG (Fig. 9G),

346 and SVZ (Fig. 9H). Some SST+ inhibitory neurons express GFP in the anterior cingulate of the

347 cortex (Fig. 9I, J), but none were observed in the DG (Fig. 9K).

348 Discussion

349 Through immunostaining for GFP in $\operatorname{tgFgfr} 1-E G F P+$ mice of the $\operatorname{tgFGFR1-}$

350 EGFPGP338Gsat line, we examined the cell specific expression of Fgfrl in the cortex, 
351 hippocampus, SVZ, hypothalamus, and cerebellum from P7 to one-month of age. In postnatal

352 brains, Fgfrl is highly expressed in the hippocampus, SVZ, hypothalamus, and in numerous cells

353 of the cortex. In the hippocampus, Fgfrl was expressed in DCX+ neuroblasts, in GFAP+ stem

354 cells and astrocytes, and Sox2+ stem cells of the SGZ, and in neurons of the CA. Furthermore,

355 Fgfrl was expressed in astrocytes, neurons, and oligodendrocyte lineages. $F g f r l$ expression in

356 cortical neurons was not restricted to a single layer and colocalized with CR+ and SST+

357 inhibitory neurons. Fgfrl expression was also observed in Bergmann glia and GFAP+ astrocytes

358 of the cerebellum.

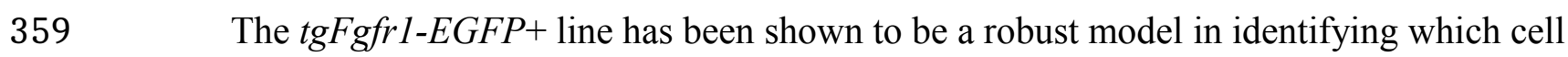

360 types express Fgfrl, corroborating the findings of previous in situ hybridization studies (el-

361 Husseini et al., 1994, Gonzalez et al., 1995, Belluardo et al., 1997, Bansal et al., 2003, Ohkubo et

362 al., 2004) and more modern molecular profiling studies (Lovatt et al., 2007, Cahoy et al., 2008,

363 Doyle et al., 2008, Azim et al., 2012). This transgenic line gives the added benefit of allowing

364 simple identification of the subtype of cells expressing Fgfrl by immunofluorescence staining,

365 since GFP is regulated by the Fgfrl promoter. Unlike the use of antibodies for FGFR1, which

366 may have cross reactivity with similar FGFR family members, we can have greater confidence

367 that we are identifying $F g f r l$ expression accurately within a cell.

368 Previous studies have shown that inactivation of FGFR1/FGFR2 and

369 FGFR1/FGFR2/FGFR3 signaling in the developing dorsal VZ results in premature depletion of

370 radial glial stem cells and a smaller cortex, whereas loss of Fgfrl alone is sufficient to result in

371 reduced hippocampal volume and reduced hippocampal stem cell proliferation during

372 embryogenesis and the early postnatal period (Ohkubo et al., 2004, Kang et al., 2009, Stevens et

373 al., 2010b, Rash et al., 2011). Our studies of Fgfrl expression in embryos and at P1 will be

374 described elsewhere, but support the role of FGFR1 in telencephalic development. At P7, Fgfr1

375 was expressed in BLBP positive cells. At this age, the BLBP+ radial glial cells are undergoing

376 soma translocation and differentiating into astrocytes of the cortical parenchyma. FGF signaling 
377 may be participating in the soma translocation process, as previously described for the glial cells

378 of the indusium griseum (Smith et al., 2006), or it may be a general factor expressed by

379 astrocytes since a majority of GFAP+ cells expressed GFP. It is interesting to note that as animals

380 matured from P7 to one-month of age, the relative amount of GFAP/GFP colocalization was

381 increased. This may reflect a maturation of astrocytic glia from BLBP expressing radial glia stem

382 cells undergoing gliogenesis and soma translocation to mature astrocytes that express higher

383 levels of GFAP. BLBP is also expressed in Bergmann glia of the cerebellum, which are cells that

384 have dual roles as stem cells and as a scaffold for granule cell neuron migration and alignment of

385 Purkinje neuron dendrites. The finding that Fgfrl is expressed within these cells is consistent

386 with the demonstrated occurrence of cooperative signaling between FGFR1 and FGFR2 in the

387 formation of the cerebellum, and specifically, in the morphology and pial attachment of

388 Bergmann glia of the cerebellar anlage (Lin et al., 2009, Muller Smith et al., 2012). FGFR1 may

389 be playing dual roles in these cells as a factor that supports their proliferation, as well as

390 structural morphology, potentially by interactions with cell adhesion molecules (Williams et al.,

391 1994, Polanska et al., 2009).

392 At P7, and one month, Fgfrl was expressed in the DG and CA regions of the

393 hippocampus, as well as in the SVZ, hypothalamus, and all layers of the cortex. In the DG,

394 expression is primarily found in stem cells as well as DCX positive cells. The Fgfrl expressing

395 cells in the CA region at P7 and 1 month colocalize with GFAP positive astrocytes and NeuN

396 positive neurons in the stratum pyramidale. Fgfrl expression within GFAP+, and SOX2+ positive

397 cells of the SGZ in the DG indicates that FGFR signaling is contributing to stem cell maintenance

398 and proliferation in the DG, and that alterations in FGFR signaling may contribute to depletion of

399 DG stem cells (Ohkubo et al., 2004). As reviewed by Patricio et al. 2013, reduced hippocampal

400 proliferation has been observed in animal models of depression, and antidepressant therapies all

401 promote either hippocampal proliferation or the survival and integration of newborn neurons 
402 (Patricio et al., 2013). FGFR signaling also participates in development of hippocampal

403 synaptogenesis (Cambon et al., 2004, Umemori et al., 2004, Terauchi et al., 2010). Activation of

404 FGFR1 promotes synapse formation in hippocampal neurons (Cambon et al., 2004, Terauchi et

405 al., 2010, Dabrowski et al., 2015). The expression of Fgfrl in DCX positive cells of the

406 hippocampus, as well as neurons in the CA region supports the evidence that FGFR1 plays

407 additional roles in synapse formation and integration into the hippocampal circuitry. These

408 findings have implications for hippocampal function in HPA axis regulation. Changes in Fgfrl

409 expression, and FGF2 levels in the hippocampus are linked to major depression and anxiety, as

410 well as to responses to antidepressants (Evans et al., 2004, Newton and Duman, 2004, Gaughran

411 et al., 2006, Turner et al., 2008, Elsayed et al., 2012). It is hypothesized that Fgf2 and Fgfrl are

412 downregulated in depression and anxiety, and this downregulation can be partially reversed by

413 antidepressant treatment (Turner et al., 2012b, a). The chronic unpredictable stress model causes

414 anhedonia and is a model of depression that results in decreased (mRNA) Fgfrl levels in the

415 prefrontal cortex (Elsayed et al., 2012). Antidepressant treatment resulted in increased (mRNA)

416 Fgf2 levels, and the antidepressant effects could be blocked by an FGFR1 inhibitor. These

417 authors further showed that FGF2 administration also had an antidepressant effect (Elsayed et al.,

418 2012). The $\operatorname{tg} f g f r l-E G F P+$ mouse line can be utilized to further examine the effects of stress and

419 depression models on Fgfrl expression.

420 GFAP positive astrocytes and BLBP cells in the SVZ at P7 are expressing GFP,

421 indicating that stem cells of the SVZ express Fgfrl. GFAP positive astrocytes at 1 month also

422 express $F g f r l$. Our findings in the SVZ are consistent with studies of single cell transcriptomics

423 of the SVZ (Azim et al., 2012, Azim et al., 2015, Llorens-Bobadilla et al., 2015). For example,

424 molecular studies have identified that CD133+ stem cells of the pallium, capable of generating

425 neurons or glia, have higher levels of Fgfrl mRNA compared to other SVZ cell types of the

426 lateral SVZ (Azim et al., 2012). Llorens-Bobadilla et al. 2015, identified subpopulations of cells 
427 within the SVZ via principle component analysis of co-expressed gene transcripts from single

428 cells, and identified that $F g f r l$ was enriched in Neural Stem Cells (NSCs) that express glial/NSC

429 markers such as Fabp7 (BLBP), Slcla3 (GLAST), Hes5, and Aldh1l1. Fgfr1 was co-expressed

430 with Category III cells in that study, which included dynamically regulated genes that change

431 expression as NSC go from a quiescent state to an activated state (Llorens-Bobadilla et al., 2015).

432 Future studies could employ $\operatorname{tg} f g f r l-E G F P+$ mice to explore the expression of $F g f r l$ during

433 remyelination and response to injury. Fgfrl expressing cells were also colocalized with SOX2

434 positive cells at 1 month. At P7 and 1 month, Fgfrl expressing cells in the SVZ do not colocalize

435 with DCX positive neuroblasts and NeuN positive neurons, as confirmed by single cell

436 transcriptomics studies. Thus, DCX positive cells express Fgfrl in one of the postnatal

437 neurogenic regions - the DG. The difference in Fgfrl expression observed between DCX positive

438 cells of the DG and SVZ implies that the staining in DCX positive cells of the hippocampus is

439 not due to residual GFP protein that has not been degraded once a daughter cell born from a stem

440 cell stops expressing $F g f r l$, suggesting we can further accurately identify $F g f r l$ expression within

441 cells using this transgenic model. An alternative explanation is that the lack of DCX in the

442 neurons born from stem cells in the SVZ is that they have a completely different profile and fate

443 (olfactory bulb neurons) compared to the newborn granule neurons of the hippocampus, and thus,

444 would not be expected to express Fgfrl in the same way.

$445 \quad$ Most GFAP positive astrocytes throughout the cortex coexpressed $F g f r l$ at similar levels,

446 and the majority of the Fgfrl expressing cells were GFAP+ astrocytes. Fgfrl expression seemed

447 to be a general feature of GFAP positive cells and glial stem cells throughout development. A

448 minority of Fgfrl expressing cells were NeuN positive neurons at P7 and one month. While it

449 was previously believed that $F g f r 2$ is expressed in glia and that $F g f r 1$ is mostly expressed by

450 neuronal populations in the adult cortex, our findings support the view that most of the cortical

451 cells expressing Fgfrl in the adult brain are, in fact, astrocytes or oligodendrocytes (Turner et al., 
452 2012a). In this study we see that most GFAP positive astrocytes express Fgfrl and a small

453 proportion of NeuN positive neurons express Fgfrl in one-month old mice. A higher percentage

454 of Fgfrl expressing cells are GFAP positive astrocytes than NeuN positive neurons. Thus,

455 astrocytes constitute a majority of Fgfrl expressing cells in the adult brain. This idea is consistent

456 with previous mRNA profiling of astrocytes in which $F g f r l$ was identified as a gene with

457 enriched expression in astrocytes as compared to other cell types in the brain (Lovatt et al., 2007,

458 Cahoy et al., 2008, Doyle et al., 2008).

459 An imbalance of excitatory and inhibitory neurons, along with hyperactivity has been

460 documented in certain neurological disorders (Benes et al., 2000, Volk et al., 2000, Kalanithi et

461 al., 2005, Akbarian and Huang, 2006, Hashimoto et al., 2008, Kataoka et al., 2010, Gonzalez-

462 Burgos et al., 2011, Volk and Lewis, 2013). Inactivation of Fgfrl leads to a decrease in the

463 abundance of parvalbumin interneurons in the cortex and is associated with an increase in

464 hyperactivity (Muller Smith et al., 2008). A subsequent study demonstrated that a decrease in

465 interneurons occurs postnatally and that Fgfrl expression does not occur in parvalbumin

466 expressing interneurons (Smith et al., 2014). Astrocytes lacking Fgfrl were less capable of

467 supporting the maturation of Gad67 expressing cells than control astrocytes. Here, we find that

$468 F g f r l$ is expressed by a majority of astrocytes in the cortex and hippocampus throughout the

469 maturational period of parvalbumin positive interneurons, further supporting the importance for

470 FGFR1 signaling in astrocytes. Current studies are seeking to explore how FGFR1 signaling

471 within astrocytes contributes to interneuron maturation.

472 Here, we tested other interneuron markers, including GAD67, calretinin, and

473 somatostatin. At one month, GAD67, a marker for inhibitory neurons, colocalizes with Fgfrl

474 expressing cells in the cortex and not in the DG. Calretinin interneurons express Fgfr 1 throughout

475 the cortex, and in the DG, whereas somatostatin interneurons express Fgfrl at the anterior

476 cingulate of the cortex. Brandt et al., 2003 demonstrated newborn calretinin positive cells in the 
477 DG do not express GABA (Brandt et al., 2003), offering a probable explanation as to why

478 GAD67 is not observed colocalizing with Fgfrl expressing cells in the DG.

479 The hypothalamus, responsible for controlling hormonal production, stress regulation, and

480 feeding behaviors, has been found to contain a neural stem/progenitor cell niche (Robins et al.,

481 2013). Our results show that GFAP positive astrocytes are Fgfrl expressing cells. The

482 morphology and location of the Fgfrl expressing cells are consistent with the cells being

483 tanycytes of the hypothalamus (Robins et al., 2013). The median eminence of the hypothalamus

484 contains Fgfrl expressing cells that also express SOX2. Fgfrl expressing cells that were not

485 identified are similar in morphology and location to the neurons that release gonadotropin-

486 releasing hormone (GNRH1). These results are in congruence with a study, which demonstrated

487 FGFR1's role in targeting of GNRH1 axons to the median eminence (Gill and Tsai, 2006, Ojeda

488 et al., 2008). Therefore, understanding FGFR signaling can give further insight to the

489 hypothalamic regulation of homeostasis.

490 Conclusion

491 FGFR1 has been implicated as having multiple functions in CNS development,

492 homeostasis, and behavior, but defining the cellular basis of its functions depends on having a

493 clear understanding of which cell types the Fgfrl gene is expressed in, and when. The GENSAT

494 project was envisioned as a resource that would provide the tools for such detailed studies

495 (Heintz, 2004). Here, we have extended the previously published in situ based studies and online

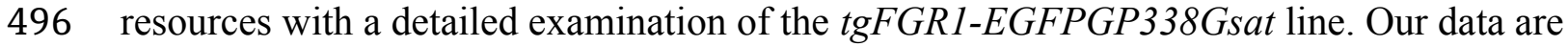

497 congruent with in situ studies, but with the added feature of double immunofluorescence with

498 glial and neuronal markers, and a quantification of the relative expression in glial versus neuronal

499 cells in the young adult brain. We here find Fgfrl promoter driven GFP expression in a variety of

500 stem cells of the CNS including the young adult SVZ, young adult SGZ, cerebellar Bergmann

501 Glia, and SOX2+ cells of the hypothalamus (summarized in Table 4). An additional study of

502 Fgfrl expression in embryonic and perinatal stem cells will be described elsewhere. We also find 
503 that Fgfrl is expressed predominantly in glia in the young adult brain, although significant

504 expression in DCX+ positive neuroblasts of the hippocampus was also observed. This was in 505 stark contrast to DCX+ neuroblasts of the RMS. Our findings may shed light on the participation 506 of FGF2/FGFR1 signaling in determining anxiety and mood, where a neuronal role for FGFR1

507 has been hypothesized (Turner et al., 2012a). Future studies are needed to determine whether

508 Fgfrl expression colocalizes with other markers, such as S100ß, O4, and NG2 at embryonic and

509 postnatal time points. Since Gfap is not expressed in all astrocytes, S100ß (glial specific marker

510 primarily expressed in astrocytes, but also in some ependymal cells) would be a good marker to

511 further explore $F g f r 1$ expression. The $\operatorname{tg} F g f r 1-E G F P+$ model can also be used to study additional

512 stages in development, or Fgfrl expression after environmental manipulations previously shown

513 to alter Fgfrl expression, including animal models for induced depression such as social defeat

514 stress.

515 Acknowledgements

516 The authors wish to thank Darryl Williams, Deborah June Rogers, Lori Rubin and Marques

517 Jackson, for technical assistance, and Glen Watson and Caryl Chlan for manuscript review.

\section{References}

519 Akbarian S, Huang HS (2006) Molecular and cellular mechanisms of altered GAD1/GAD67 520 expression in schizophrenia and related disorders. Brain Res Rev 52:293-304.

521 Azim K, Hurtado-Chong A, Fischer B, Kumar N, Zweifel S, Taylor V, Raineteau O (2015)

522 Transcriptional Hallmarks of Heterogeneous Neural Stem Cell Niches of the

523 Subventricular Zone. Stem Cells 33:2232-2242.

524 Azim K, Raineteau O, Butt AM (2012) Intraventricular injection of FGF-2 promotes generation 525 of oligodendrocyte-lineage cells in the postnatal and adult forebrain. Glia 60:1977-1990. 
526 Bansal R, Lakhina V, Remedios R, Tole S (2003) Expression of FGF receptors 1, 2, 3 in the

527 embryonic and postnatal mouse brain compared with Pdgfralpha, Olig2 and Plp/dm20:

528 implications for oligodendrocyte development. Dev Neurosci 25:83-95.

529 Belluardo N, Wu G, Mudo G, Hansson AC, Pettersson R, Fuxe K (1997) Comparative

530 localization of fibroblast growth factor receptor-1, -2 , and -3 mRNAs in the rat brain: in

531 situ hybridization analysis. J Comp Neurol 379:226-246.

532 Benes FM, Todtenkopf MS, Logiotatos P, Williams M (2000) Glutamate decarboxylase(65)-

533 immunoreactive terminals in cingulate and prefrontal cortices of schizophrenic and

534 bipolar brain. J Chem Neuroanat 20:259-269.

535 Blak AA, Naserke T, Weisenhorn DM, Prakash N, Partanen J, Wurst W (2005) Expression of Fgf

536 receptors 1,2 , and 3 in the developing mid- and hindbrain of the mouse. Dev Dyn

$537 \quad 233: 1023-1030$.

538 Brandt MD, Jessberger S, Steiner B, Kronenberg G, Reuter K, Bick-Sander A, von der Behrens

539 W, Kempermann G (2003) Transient calretinin expression defines early postmitotic step

540 of neuronal differentiation in adult hippocampal neurogenesis of mice. Mol Cell Neurosci

$541 \quad 24: 603-613$.

542 Cahoy JD, Emery B, Kaushal A, Foo LC, Zamanian JL, Christopherson KS, Xing Y, Lubischer

543 JL, Krieg PA, Krupenko SA, Thompson WJ, Barres BA (2008) A transcriptome database

544 for astrocytes, neurons, and oligodendrocytes: a new resource for understanding brain

545 development and function. J Neurosci 28:264-278.

546 Cambon K, Hansen SM, Venero C, Herrero AI, Skibo G, Berezin V, Bock E, Sandi C (2004) A

547 synthetic neural cell adhesion molecule mimetic peptide promotes synaptogenesis,

548 enhances presynaptic function, and facilitates memory consolidation. J Neurosci 24:4197-

5494204. 
550 Chaker Z, Codega P, Doetsch F (2016) A mosaic world: puzzles revealed by adult neural stem 551 cell heterogeneity. Wiley Interdiscip Rev Dev Biol 5:640-658.

552 Chellaiah A, Yuan W, Chellaiah M, Ornitz DM (1999) Mapping ligand binding domains in 553 chimeric fibroblast growth factor receptor molecules. Multiple regions determine ligand $554 \quad$ binding specificity. J Biol Chem 274:34785-34794.

555 Cholfin JA, Rubenstein JL (2007) Genetic regulation of prefrontal cortex development and 556 function. Novartis Found Symp 288:165-173; discussion 173-167, 276-181.

557 Dabrowski A, Terauchi A, Strong C, Umemori H (2015) Distinct sets of FGF receptors sculpt 558 excitatory and inhibitory synaptogenesis. Development 142:1818-1830.

559 Doyle JP, Dougherty JD, Heiman M, Schmidt EF, Stevens TR, Ma G, Bupp S, Shrestha P, Shah 560 RD, Doughty ML, Gong S, Greengard P, Heintz N (2008) Application of a translational 561 profiling approach for the comparative analysis of CNS cell types. Cell 135:749-762.

562 el-Husseini Ae-D, Paterson JA, Shiu RP (1994) Basic fibroblast growth factor (bFGF) and two of 563 its receptors, FGFR1 and FGFR2: gene expression in the rat brain during postnatal 564 development as determined by quantitative RT-PCR. Mol Cell Endocrinol 104:191-200.

565 Elsayed M, Banasr M, Duric V, Fournier NM, Licznerski P, Duman RS (2012) Antidepressant 566 effects of fibroblast growth factor-2 in behavioral and cellular models of depression. Biol $567 \quad$ Psychiatry 72:258-265.

568 Evans SJ, Choudary PV, Neal CR, Li JZ, Vawter MP, Tomita H, Lopez JF, Thompson RC, Meng 569 F, Stead JD, Walsh DM, Myers RM, Bunney WE, Watson SJ, Jones EG, Akil H (2004) Dysregulation of the fibroblast growth factor system in major depression. Proc Natl Acad

572 Fagel DM, Ganat Y, Cheng E, Silbereis J, Ohkubo Y, Ment LR, Vaccarino FM (2009) Fgfr1 is 573 required for cortical regeneration and repair after perinatal hypoxia. J Neurosci 29:12021211. 
575 Fiorelli R, Azim K, Fischer B, Raineteau O (2015) Adding a spatial dimension to postnatal

576 ventricular-subventricular zone neurogenesis. Development 142:2109-2120.

577 Fukuchi-Shimogori T, Grove EA (2001) Neocortex patterning by the secreted signaling molecule

$578 \quad$ FGF8. Science 294:1071-1074.

579 Furusho M, Dupree JL, Nave KA, Bansal R (2012) Fibroblast growth factor receptor signaling in 580 oligodendrocytes regulates myelin sheath thickness. J Neurosci 32:6631-6641.

581 Furusho M, Roulois AJ, Franklin RJ, Bansal R (2015) Fibroblast growth factor signaling in 582 oligodendrocyte-lineage cells facilitates recovery of chronically demyelinated lesions but 583 is redundant in acute lesions. Glia 63:1714-1728.

584 Garcia-Gonzalez D, Clemente D, Coelho M, Esteban PF, Solissi-Yanicostas N, de Castro F 585 (2010) Dynamic roles of FGF-2 and Anosmin-1 in the migration of neuronal precursors

586

587 from the subventricular zone during pre- and postnatal development. Experimental Neurology 222:285-295.

588 Gaughran F, Payne J, Sedgwick PM, Cotter D, Berry M (2006) Hippocampal FGF-2 and FGFR1 589 mRNA expression in major depression, schizophrenia and bipolar disorder. Brain Res $590 \quad$ Bull 70:221-227.

591 Gill JC, Tsai PS (2006) Expression of a dominant negative FGF receptor in developing GNRH1 592 neurons disrupts axon outgrowth and targeting to the median eminence. Biol Reprod $593 \quad 74: 463-472$.

594 Gonzalez AM, Berry M, Maher PA, Logan A, Baird A (1995) A comprehensive analysis of the 595 distribution of FGF-2 and FGFR1 in the rat brain. Brain Res 701:201-226.

596 Gonzalez-Burgos G, Fish KN, Lewis DA (2011) GABA neuron alterations, cortical circuit 597 dysfunction and cognitive deficits in schizophrenia. Neural Plast 2011:723184. 
598 Gutin G, Fernandes M, Palazzolo L, Paek H, Yu K, Ornitz DM, McConnell SK, Hebert JM

599 (2006) FGF signalling generates ventral telencephalic cells independently of SHH.

600 Development 133:2937-2946.

601 Hashimoto T, Arion D, Unger T, Maldonado-Aviles JG, Morris HM, Volk DW, Mirnics K, Lewis

602 DA (2008) Alterations in GABA-related transcriptome in the dorsolateral prefrontal

603 cortex of subjects with schizophrenia. Mol Psychiatry 13:147-161.

604 Hebert JM (2011) FGFs: Neurodevelopment's Jack-of-all-Trades - How Do They Do it? Front

$605 \quad$ Neurosci 5:133.

606 Heintz N (2004) Gene expression nervous system atlas (GENSAT). Nat Neurosci 7:483.

607 Iwata T, Hevner RF (2009) Fibroblast growth factor signaling in development of the cerebral

608 cortex. Dev Growth Differ 51:299-323.

609 Kalanithi PS, Zheng W, Kataoka Y, DiFiglia M, Grantz H, Saper CB, Schwartz ML, Leckman JF,

610 Vaccarino FM (2005) Altered parvalbumin-positive neuron distribution in basal ganglia of

611 individuals with Tourette syndrome. Proc Natl Acad Sci U S A 102:13307-13312.

612 Kang W, Balordi F, Su N, Chen L, Fishell G, Hebert JM (2014) Astrocyte activation is suppressed

613 in both normal and injured brain by FGF signaling. Proc Natl Acad Sci U S A 111:E2987-

6142995.

615 Kang W, Wong LC, Shi SH, Hebert JM (2009) The transition from radial glial to intermediate

616 progenitor cell is inhibited by FGF signaling during corticogenesis. J Neurosci 29:14571-

$617 \quad 14580$.

618 Kataoka Y, Kalanithi PS, Grantz H, Schwartz ML, Saper C, Leckman JF, Vaccarino FM (2010)

619 Decreased number of parvalbumin and cholinergic interneurons in the striatum of

620 individuals with Tourette syndrome. J Comp Neurol 518:277-291. 
621 Korada S, Zheng W, Basilico C, Schwartz ML, Vaccarino FM (2002) Fibroblast growth factor 2 622 is necessary for the growth of glutamate projection neurons in the anterior neocortex. $\mathrm{J}$ $623 \quad$ Neurosci 22:863-875.

624 Lin Y, Chen L, Lin C, Luo Y, Tsai RY, Wang F (2009) Neuron-derived FGF9 is essential for 625 scaffold formation of Bergmann radial fibers and migration of granule neurons in the 626 cerebellum. Dev Biol 329:44-54.

627 Llorens-Bobadilla E, Zhao S, Baser A, Saiz-Castro G, Zwadlo K, Martin-Villalba A (2015) 628 Single-Cell Transcriptomics Reveals a Population of Dormant Neural Stem Cells that 629 Become Activated upon Brain Injury. Cell Stem Cell 17:329-340.

630 Lovatt D, Sonnewald U, Waagepetersen HS, Schousboe A, He W, Lin JH, Han X, Takano T, 631 Wang S, Sim FJ, Goldman SA, Nedergaard M (2007) The transcriptome and metabolic 632 gene signature of protoplasmic astrocytes in the adult murine cortex. J Neurosci $633 \quad 27: 12255-12266$.

634 Muller Smith K, Fagel DM, Stevens HE, Rabenstein RL, Maragnoli ME, Ohkubo Y, Picciotto 635 MR, Schwartz ML, Vaccarino FM (2008) Deficiency in inhibitory cortical interneurons 636 associates with hyperactivity in fibroblast growth factor receptor 1 mutant mice. Biol 637 Psychiatry 63:953-962.

638 Muller Smith K, Williamson TL, Schwartz ML, Vaccarino FM (2012) Impaired motor 639 coordination and disrupted cerebellar architecture in Fgfr1 and Fgfr2 double knockout 640 mice. Brain Res 1460:12-24.

641 Newton SS, Duman RS (2004) Regulation of neurogenesis and angiogenesis in depression. Curr $642 \quad$ Neurovasc Res 1:261-267.

643 Ohkubo Y, Uchida AO, Shin D, Partanen J, Vaccarino FM (2004) Fibroblast growth factor 644 receptor 1 is required for the proliferation of hippocampal progenitor cells and for 645 hippocampal growth in mouse. J Neurosci 24:6057-6069. 
646 Ojeda SR, Lomniczi A, Sandau US (2008) Glial-gonadotrophin hormone (GnRH) neurone

647 interactions in the median eminence and the control of GnRH secretion. J

$648 \quad$ Neuroendocrinol 20:732-742.

649 Ornitz DM, Itoh N (2015) The Fibroblast Growth Factor signaling pathway. Wiley Interdiscip

650 Rev Dev Biol 4:215-266.

651 Patricio P, Mateus-Pinheiro A, Sousa N, Pinto L (2013) Re-cycling paradigms: cell cycle

652 regulation in adult hippocampal neurogenesis and implications for depression. Mol

$653 \quad$ Neurobiol 48:84-96.

654 Polanska UM, Fernig DG, Kinnunen T (2009) Extracellular interactome of the FGF receptor-

655 ligand system: complexities and the relative simplicity of the worm. Dev Dyn 238:277-

656293.

657 Rash BG, Lim HD, Breunig JJ, Vaccarino FM (2011) FGF signaling expands embryonic cortical

658 surface area by regulating Notch-dependent neurogenesis. J Neurosci 31:15604-15617.

659 Rash BG, Tomasi S, Lim HD, Suh CY, Vaccarino FM (2013) Cortical gyrification induced by

660 fibroblast growth factor 2 in the mouse brain. J Neurosci 33:10802-10814.

661 Robins SC, Stewart I, McNay DE, Taylor V, Giachino C, Goetz M, Ninkovic J, Briancon N,

662 Maratos-Flier E, Flier JS, Kokoeva MV, Placzek M (2013) alpha-Tanycytes of the adult

663 hypothalamic third ventricle include distinct populations of FGF-responsive neural

664 progenitors. Nat Commun 4:2049.

665 Rodriguez EM, Blazquez JL, Pastor FE, Pelaez B, Pena P, Peruzzo B, Amat P (2005)

666 Hypothalamic tanycytes: a key component of brain-endocrine interaction. Int Rev Cytol $667 \quad 247: 89-164$.

668 Salmaso N, Stevens HE, McNeill J, ElSayed M, Ren Q, Maragnoli ME, Schwartz ML, Tomasi S, 669 Sapolsky RM, Duman R, Vaccarino FM (2016) Fibroblast Growth Factor 2 Modulates 

Receptors. Biol Psychiatry.

672 Shin DM, Korada S, Raballo R, Shashikant CS, Simeone A, Taylor JR, Vaccarino F (2004) Loss

673 of glutamatergic pyramidal neurons in frontal and temporal cortex resulting from attenuation of FGFR1 signaling is associated with spontaneous hyperactivity in mice. J

675 Neurosci 24:2247-2258.

676 Smith KM, Maragnoli ME, Phull PM, Tran KM, Choubey L, Vaccarino FM (2014) Fgfr1 inactivation in the mouse telencephalon results in impaired maturation of interneurons expressing parvalbumin. PLoS One 9:e103696.

679

680

681

682 683
Smith KM, Ohkubo Y, Maragnoli ME, Rasin MR, Schwartz ML, Sestan N, Vaccarino FM (2006) Midline radial glia translocation and corpus callosum formation require FGF signaling. Nat Neurosci.

Stevens HE, Smith KM, Maragnoli ME, Fagel D, Borok E, Shanabrough M, Horvath TL, Vaccarino FM (2010a) Fgfr2 is required for the development of the medial prefrontal cortex and its connections with limbic circuits. J Neurosci 30:5590-5602.

Stevens HE, Smith KM, Rash BG, Vaccarino FM (2010b) Neural stem cell regulation, fibroblast growth factors, and the developmental origins of neuropsychiatric disorders. Front Neurosci 4.

Storm EE, Garel S, Borello U, Hebert JM, Martinez S, McConnell SK, Martin GR, Rubenstein JL (2006) Dose-dependent functions of Fgf8 in regulating telencephalic patterning centers. Development 133:1831-1844.

Storm EE, Rubenstein JL, Martin GR (2003) Dosage of Fgf8 determines whether cell survival is positively or negatively regulated in the developing forebrain. Proc Natl Acad Sci U S A 100:1757-1762. 
694 Terauchi A, Johnson-Venkatesh EM, Toth AB, Javed D, Sutton MA, Umemori H (2010) Distinct 695 FGFs promote differentiation of excitatory and inhibitory synapses. Nature 465:783-787. 696 Tole S, Gutin G, Bhatnagar L, Remedios R, Hebert JM (2006) Development of midline cell types 697 and commissural axon tracts requires Fgfr1 in the cerebrum. Dev Biol 289:141-151.

698 Turner CA, Calvo N, Frost DO, Akil H, Watson SJ (2008) The fibroblast growth factor system is 699 downregulated following social defeat. Neurosci Lett 430:147-150.

700 Turner CA, Watson SJ, Akil H (2012a) The fibroblast growth factor family: neuromodulation of $701 \quad$ affective behavior. Neuron 76:160-174.

702 Turner CA, Watson SJ, Akil H (2012b) Fibroblast growth factor-2: an endogenous antidepressant 703 and anxiolytic molecule? Biol Psychiatry 72:254-255.

704 Umemori H, Linhoff MW, Ornitz DM, Sanes JR (2004) FGF22 and its close relatives are 705 presynaptic organizing molecules in the mammalian brain. Cell 118:257-270.

706 Vaccarino FM, Schwartz ML, Raballo R, Nilsen J, Rhee J, Zhou M, Doetschman T, Coffin JD, 707 Wyland JJ, Hung YT (1999) Changes in cerebral cortex size are governed by fibroblast 708 growth factor during embryogenesis. Nat Neurosci 2:246-253.

709 Volk DW, Austin MC, Pierri JN, Sampson AR, Lewis DA (2000) Decreased glutamic acid 710 decarboxylase67 messenger RNA expression in a subset of prefrontal cortical gamma711 aminobutyric acid neurons in subjects with schizophrenia. Arch Gen Psychiatry 57:237$712 \quad 245$.

713 Volk DW, Edelson JR, Lewis DA (2016) Altered expression of developmental regulators of 714 parvalbumin and somatostatin neurons in the prefrontal cortex in schizophrenia.

$715 \quad$ Schizophr Res.

716 Volk DW, Lewis DA (2013) Prenatal ontogeny as a susceptibility period for cortical GABA 717 neuron disturbances in schizophrenia. Neuroscience 248C:154-164. 
718 Williams EJ, Furness J, Walsh FS, Doherty P (1994) Activation of the FGF receptor underlies

719 neurite outgrowth stimulated by L1, N-CAM, and N-cadherin. Neuron 13:583-594.

Table 1. Antibodies used for Immunofluorescence Detection

\begin{tabular}{lllll}
\hline Antigen & Raised In & Dilution & Source & Marker of \\
\hline NeuN & Mouse & $1: 125$ & Millipore & Neuron \\
\hline GFAP & Rabbit & $1: 500$ & Dako Cytomation & Astrocyte \\
\hline GFP & Chicken & $1: 250$ & Abcam Inc. & GFP \\
\hline Sox2 & Rabbit & $1: 250$ & Millipore & $\begin{array}{l}\text { Neuronal } \\
\text { precursor }\end{array}$ \\
\hline Olig2 & Mouse & $1: 1000$ & Millipore & Oligodendrocyte \\
\hline DCX & Mouse & $1: 250$ & Abcam Inc & Neuroblast \\
\hline GAD67 & Mouse & $1: 1000$ & Millipore & Inhibitory neuron \\
\hline Calretinin & Rabbit & $1: 1000$ & Millipore & Inhibitory neuron \\
\hline Somatostatin & Rat & $1: 200$ & Millipore & Inhibitory neuron \\
\hline BLBP & Rabbit & $1: 1000$ & Abcam Inc. & Stem cells \\
\hline
\end{tabular}


Table 2. Parameters used for Stereological Cell Counts

\begin{tabular}{lllllll}
\hline $\begin{array}{l}\text { Time } \\
\text { Point }\end{array}$ & Area & $\begin{array}{l}\text { Counting } \\
\text { Frame } \\
(\boldsymbol{\mu m})\end{array}$ & $\begin{array}{l}\text { Grid Size } \\
(\boldsymbol{\mu m})\end{array}$ & $\begin{array}{l}\text { Dissecto } \\
\mathbf{r} \text { Height } \\
(\boldsymbol{\mu m})\end{array}$ & $\begin{array}{l}\text { Guard } \\
\text { Zone } \\
\text { Height } \\
(\boldsymbol{\mu m})\end{array}$ & $\begin{array}{l}\text { Section } \\
\text { Thickness } \\
(\boldsymbol{\mu m})\end{array}$ \\
\hline P7 & Cortex & $75 \times 75$ & $650 \times 700$ & 15 & 1 & 50 \\
\hline & DG & $75 \times 75$ & $250 \times 250$ & 15 & 1 & 50 \\
\hline & CA & $75 \times 75$ & $500 \times 500$ & 15 & 1 & 50 \\
\hline 1 month & Cortex & $75 \times 75$ & $1000 \times 1000$ & 15 & 1 & 50 \\
\hline & DG & $75 \times 75$ & $275 \times 200$ & 15 & 1 & 50 \\
\hline & CA & $75 \times 75$ & $350 \times 250$ & 15 & 1 & 50 \\
\hline
\end{tabular}


Table 3. Stereology Results for Hippocampal DG, CA, and Cortex

\begin{tabular}{|c|c|c|c|c|c|c|c|}
\hline Age & Area & $\begin{array}{l}\text { Marke } \\
\text { r }\end{array}$ & $\begin{array}{l}\text { \# of Marker } \\
+ \text { cells }\end{array}$ & $\begin{array}{l}\text { P- } \\
\text { value }\end{array}$ & \# of GFP+ cells & $\begin{array}{l}\text { \% of GFP+ cells } \\
\text { expressing } \\
\text { Marker }\end{array}$ & $\begin{array}{l}\text { \% of Marker+ } \\
\text { cells expressing } \\
\text { GFP }\end{array}$ \\
\hline \multirow[t]{3}{*}{ P7 } & DG & GFAP & $5614 \pm 467$ & 0.37 & $15974 \pm 7447$ & $24 \% \pm 8 \%$ & $50 \% \pm 8 \%$ \\
\hline & $\mathrm{CA}$ & GFAP & $51258 \pm 1741$ & 0.42 & $46413 \pm 14851$ & $50 \% \pm 5 \%$ & $43 \% \pm 9 \%$ \\
\hline & Cortex & GFAP & $\begin{array}{l}412147 \pm \\
22494\end{array}$ & 0.25 & $1220518 \pm 53849$ & $32 \% \pm 4 \%$ & $93 \% \pm 2 \%$ \\
\hline \multirow[t]{7}{*}{$\begin{array}{l}1 \\
\text { Month }\end{array}$} & DG & NeuN & $\begin{array}{l}755542 \pm \\
228698\end{array}$ & 0.52 & $243542 \pm 12945$ & $16 \% \pm 6 \%$ & $5 \% \pm 0.7 \%$ \\
\hline & & GFAP & $\begin{array}{l}149161 \pm \\
22540\end{array}$ & 0.53 & $243542 \pm 12945$ & $51 \% \pm 3 \%$ & $85 \% \pm 4 \%$ \\
\hline & $\mathrm{CA}$ & NeuN & $\begin{array}{l}670709 \pm \\
59607\end{array}$ & 0.27 & $379768 \pm 27634$ & $25 \% \pm 7 \%$ & $15 \% \pm 6 \%$ \\
\hline & & GFAP & $\begin{array}{l}286614 \pm \\
39645\end{array}$ & 0.86 & $379768 \pm 27634$ & $61 \% \pm 9 \%$ & $81 \% \pm 3 \%$ \\
\hline & Cortex & GFAP & $\begin{array}{l}1777872 \pm \\
876236\end{array}$ & 0.66 & $\begin{array}{l}2321696 \pm \\
1056829\end{array}$ & $57 \% \pm 7 \%$ & $83 \% \pm 6 \%$ \\
\hline & & NeuN & $\begin{array}{l}4962422 \pm \\
2264757\end{array}$ & 0.97 & $\begin{array}{l}2321696 \pm \\
1056829\end{array}$ & $25 \% \pm 4 \%$ & $12 \% \pm 2 \%$ \\
\hline & & Olig2 & $\begin{array}{l}800755 \pm \\
137359\end{array}$ & 0.85 & $1574962 \pm 195563$ & $29 \% \pm 0.9 \%$ & $58 \% \pm 0.08 \%$ \\
\hline
\end{tabular}


Table 4. Qualitative comparison of Fgfrl expression

\begin{tabular}{|c|c|c|c|c|c|c|c|}
\hline \multirow{2}{*}{$\begin{array}{l}\text { Time } \\
\text { Point }\end{array}$} & \multirow[t]{2}{*}{ Area } & \multicolumn{6}{|c|}{ Fgfrl Expression in Cell Types } \\
\hline & & BLBP & GFAP & SOX2 & DCX & NeuN & Olig2 \\
\hline \multirow[t]{5}{*}{ P7 } & $\mathrm{DG}$ & ++ & ++ & NA & +++ & + & \\
\hline & CA & & ++ & NA & & ++ & \\
\hline & SVZ & +++ & + & NA & & & ++ \\
\hline & Cortex & +++ & ++ & NA & & + & ++ \\
\hline & $\begin{array}{l}\text { Hypothalamu } \\
\text { s }\end{array}$ & & ++ & NA & & & \\
\hline \multirow[t]{5}{*}{1 month } & DG & & ++ & ++ & ++ & & \\
\hline & CA & & + & & & + & \\
\hline & SVZ & & ++ & ++ & & & \\
\hline & Cortex & & ++ & & & + & + \\
\hline & $\begin{array}{l}\text { Hypothalamu } \\
\text { S }\end{array}$ & & ++ & ++ & & & \\
\hline
\end{tabular}

$720 \mathrm{NA}=$ not analyzed 
721 Figure 1. Fgfrl expression in GFAP+ cells of the hippocampus at P7. GFAP (A,D) GFP (B,E)

722 immunostaining of the DG in P7 tgfgfrl-EGFP+ mice (A-C, n=3) and tgfgfrl-EGFP- littermate

723 controls (D-F, $n=3)$ demonstrated strong GFAP/GFP colocalization in cells of the SGZ

724 (arrowheads) and their radial fibers into the GCL (small arrows). GFAP and GFP immunostaining

725 of the CA region in $\operatorname{tg} f g f r l-E G F P+$ mice $(\mathbf{G}-\mathbf{I}, \mathbf{n}=3)$ and $\operatorname{tg} f g f r l-E G F P$ - controls $(\mathbf{J}-\mathbf{L}, \mathrm{n}=3)$.

726 GFP+ staining was observed in stratum pyramidale (SP) as well as in cells above (stratum oriens,

$727 \mathrm{SO}$ ) and below (stratum radiatum, SR) this layer $(\mathbf{H})$. GFAP+/GFP+ colabeling (arrowheads) was

728 observed in primarily in the SO and SR within the CA region, and in the white matter dorsal to

729 the hippocampus. Scale bar is $25 \mu \mathrm{m}$. SGZ = subgranular zone, GCL $=$ granule cell layer,

$730 \mathrm{SP}=$ stratum pyramidale. 


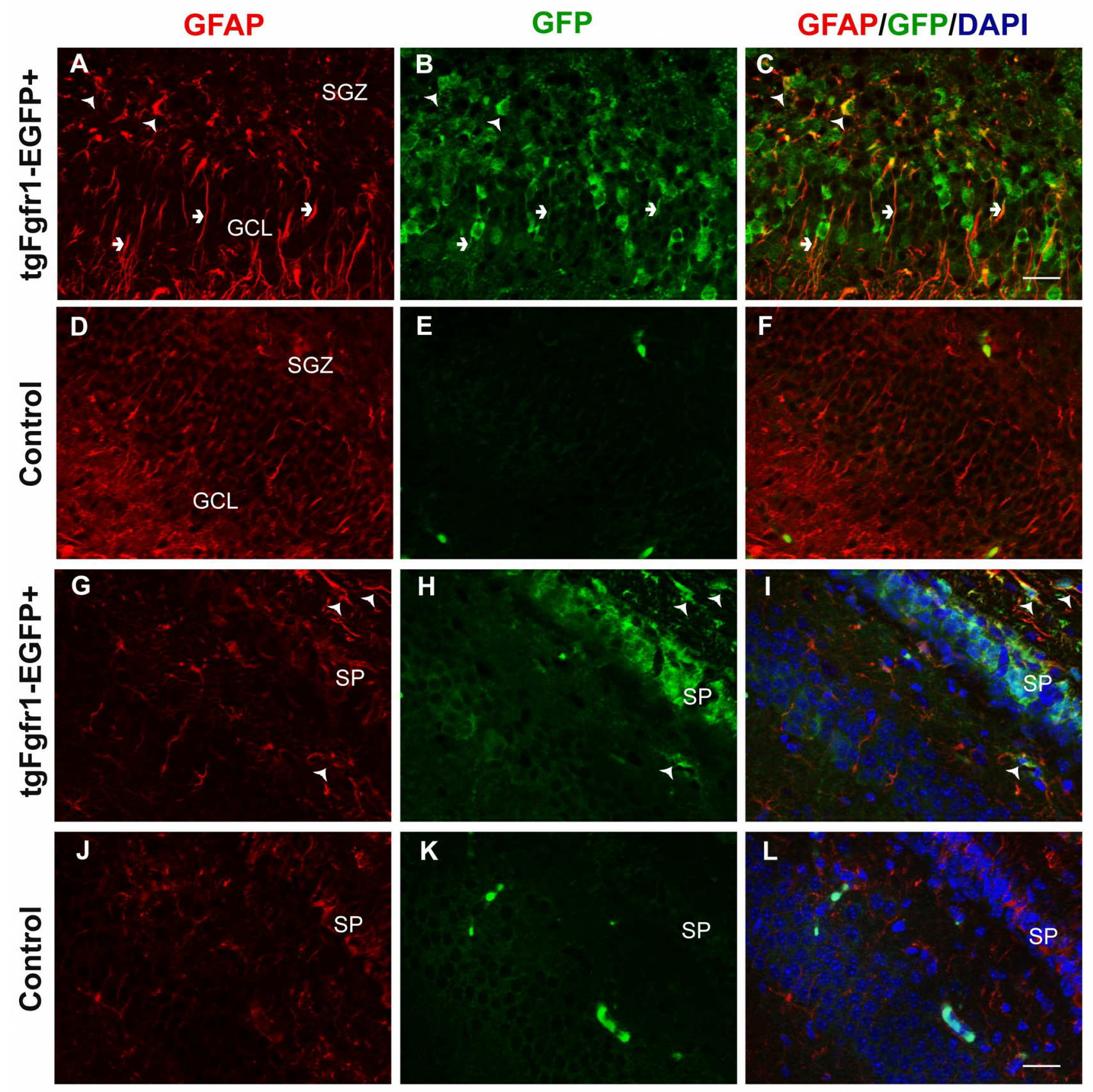


731 Figure 2. Fgfr1 expression in NeuN+ cells of the hippocampus at P7. NeuN (A,D) and GFP

$732(\mathrm{~B}, \mathrm{E})$ immunostaining of the $\mathrm{CA}$ region in $\operatorname{tg} f g f r 1-E G F P+$ mice $(\mathrm{A}-\mathrm{C}, \mathrm{n}=3)$ and $\operatorname{tg} f g f r 1-E G F P$ -

733 controls $(\mathrm{D}-\mathrm{F}, \mathrm{n}=3)$. Neun+/GFP+ staining was observed in stratum pyramidale (SP) of the CA

734 region. $\operatorname{NeuN}(\mathrm{G}, \mathrm{J})$ and $\mathrm{GFP}(\mathrm{H}, \mathrm{K})$ immunostaining of the DG in tgfgfrl-EGFP+ mice (G-I,

$735 \mathrm{n}=3)$ and $\operatorname{tg} f g f r 1-E G F P$ - controls $(\mathrm{J}-\mathrm{L}, \mathrm{n}=3)$. There was some colabeling in the granule cell layer

736 between GFP+ and NeuN+ cells. Scale bar is $25 \mu \mathrm{m}$ in A-D and $50 \mu \mathrm{m}$ in G-L. SP=stratum

737 pyramidale, $\mathrm{DG}=$ dentate gyrus. 
NeuN
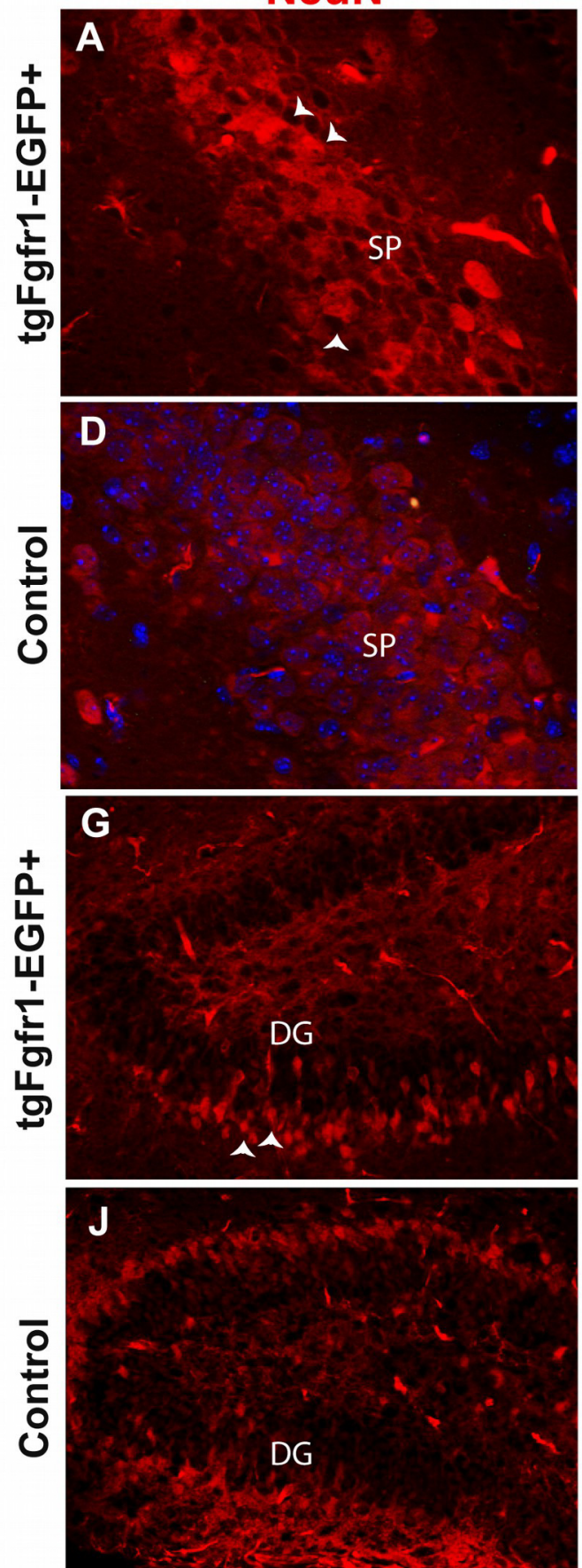

GFP

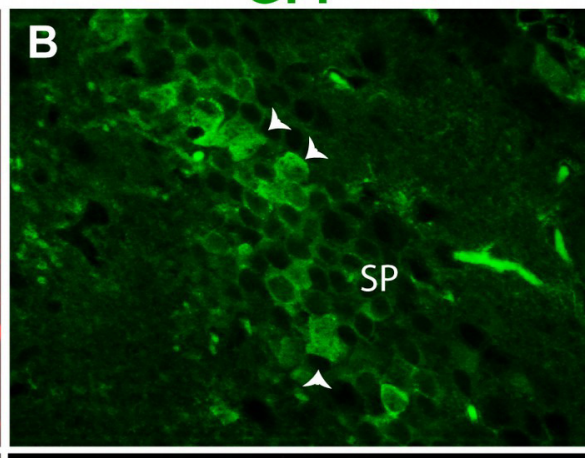

$\mathbf{E}$

SP

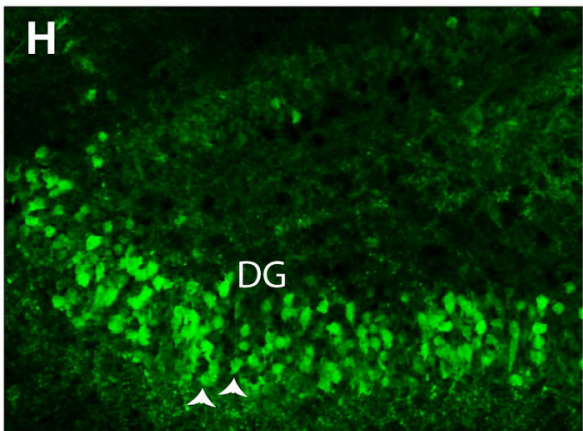

K

DG

\section{NeuN/GFP/DAPI}

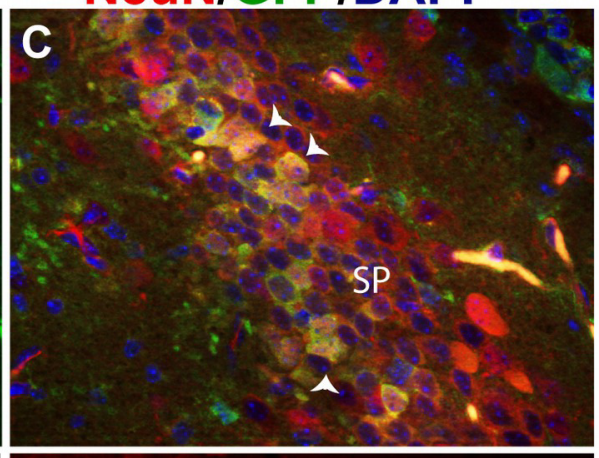

$\mathbf{F}$

$\mathrm{SP}$

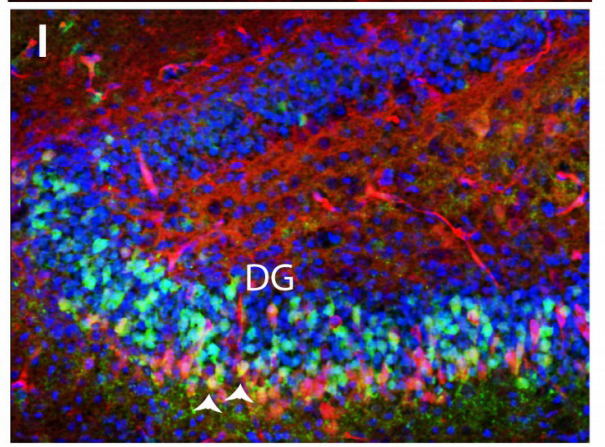

$\mathbf{L}$

DG 
738 Figure 3. Fgfr1 expression in neuroblasts of the hippocampus, and stem cells of the

739 hippocampus and SVZ at P7. DCX and GFP colocalize in neuroblasts of the P7 mice in the

740 granule cell layer of the DG in the hippocampus (A, low magnification, and B, high

741 magnification), but not in the SVZ of the lateral ventricles (C). Many of the BLBP+ cells

742 colocalize with GFP in the stem cells of the SGZ of the DG (D, low magnification, and $\mathbf{E}$, high

743 magnification), as well as stem cells in the $\operatorname{SVZ}(\mathbf{F}, \mathbf{G})$. Scale bar is $50 \mu \mathrm{m}$ in $\mathbf{A}, \mathbf{C}, \mathbf{D}, \mathbf{F}$ and $25 \mu \mathrm{m}$

744 in $\mathbf{B}$ and $\mathbf{E}$, and $12.5 \mu \mathrm{m}$ in $\mathbf{G}$. Arrows indicate examples of double labeled cells, dashed lines

745 denote SVZ. 
Manuscript to be reviewed
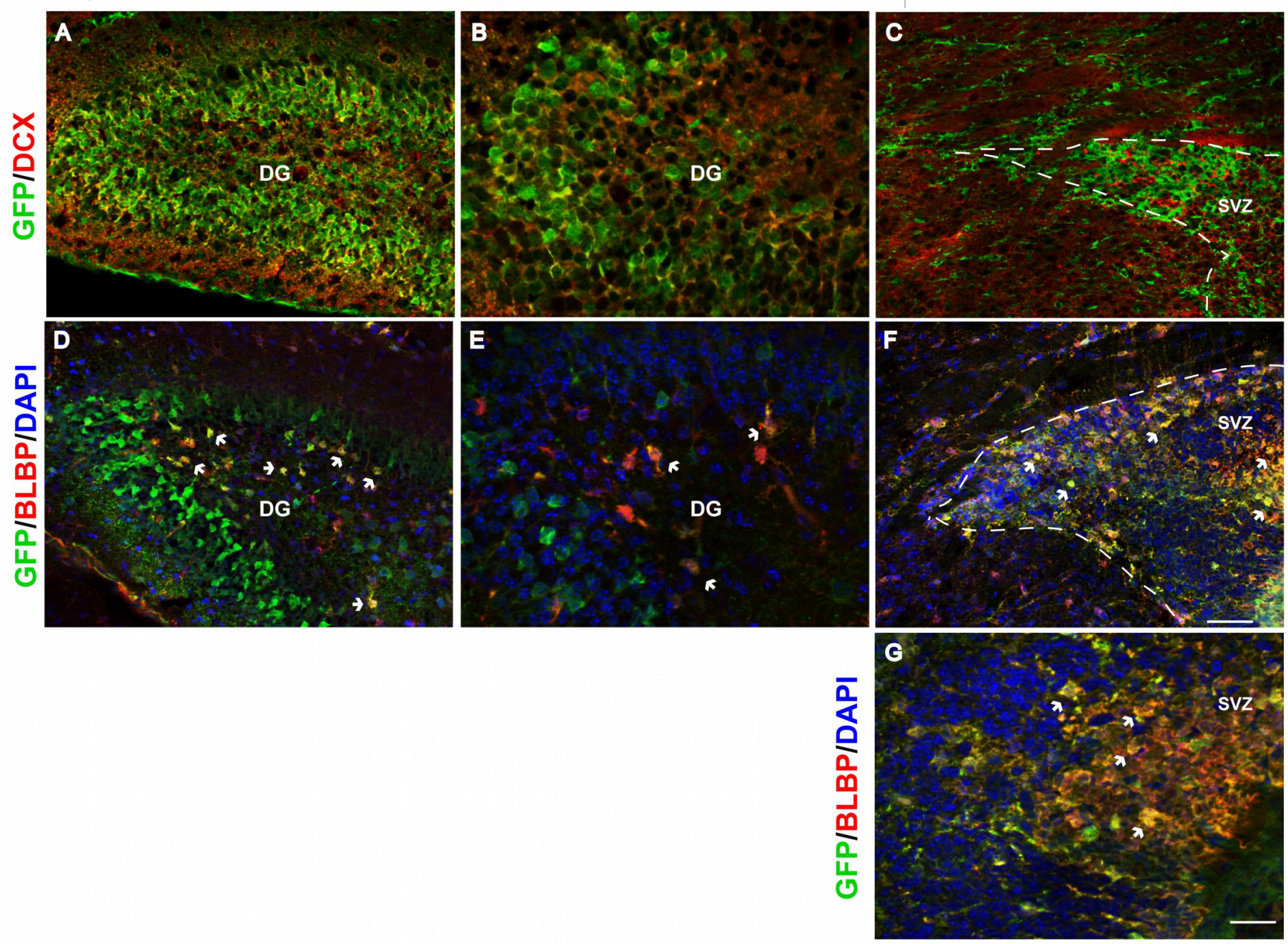
746 Figure 4. Fgfr1 expression in cortex of P7 mice. Cortical GFAP, NeuN, BLBP and GFP

747 immunostaining in P7 tgfgfrl-EGFP+ mice (A, B, D, E, G-J, n=3) and tgfgfrl-EGFP-controls

$748(\mathbf{C}, \mathbf{F}, \mathrm{n}=3) . \mathrm{GFP}+$ cells colocalize with GFAP+ cells (A, B). GFP+ cells weakly colocalize with

$749 \mathrm{NeuN}+$ at layers 5 and 6 of the cortex $(\mathbf{D}, \mathbf{E}$, dashed line separates cortical plate and subcortical

750 white matter). GFP+ cells colocalize with Olig2+ cells in the cortex (G-I) and some of the

751 OLIG2+ cells of the subcortical white matter and SVZ (J). GFP+ cells colocalize with BLBP+

752 cells throughout the layers of the cortex $(\mathbf{K}-\mathbf{M})$ as well as the BLBP+ cells and Bergmann glia of

753 the cerebellum (N). Scale bar is $50 \mu \mathrm{m} .1,2,3,4,5,6=$ layers of the cortex. Arrows indicate

754 examples of double labeled cells. 


\section{tgFgfr1-EGFP+}
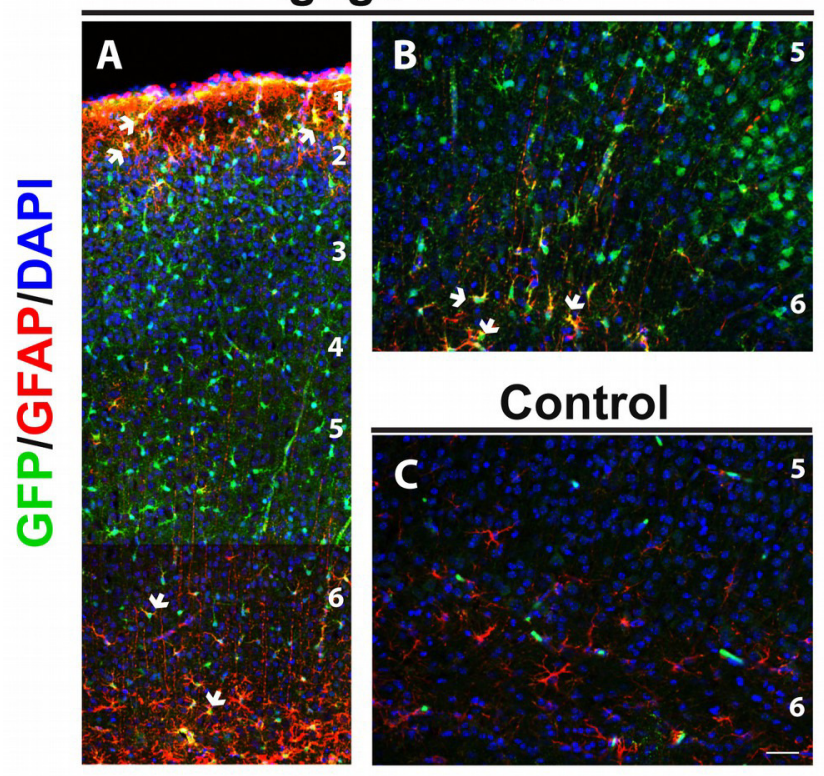

tgFgfr1-EGFP+

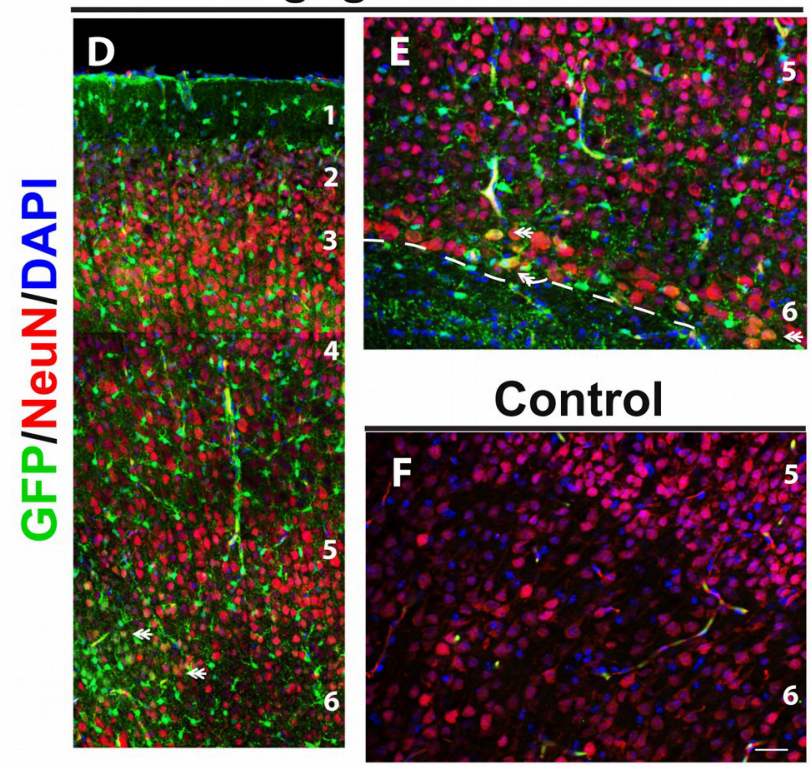

tgFgfr 1-EGFP+
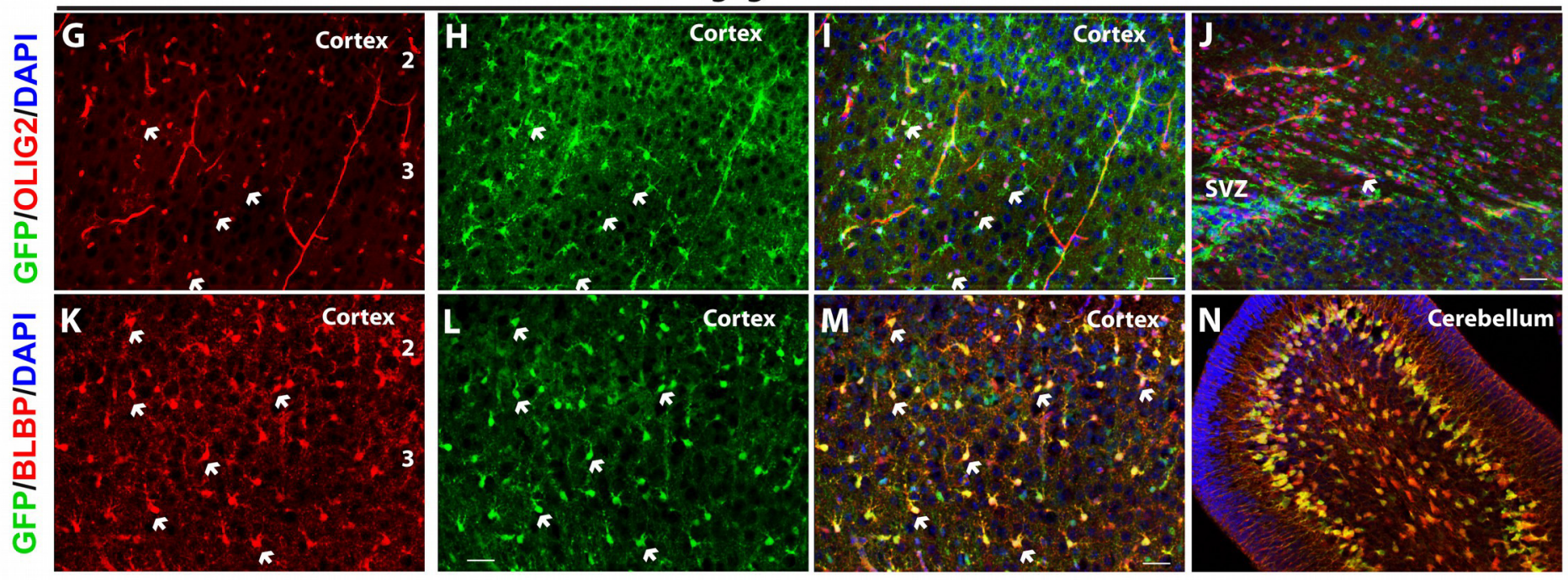
755 Figure 5. Fgfr 1 expression in the dentate gyrus and CA of 1-month mice. A majority of

756 SOX2 + cells $(\mathbf{A}, \mathbf{C})$ in the DG of $\operatorname{tg} f g f r 1-E G F P+$ mice colocalize with GFP $(\mathbf{B}, \mathbf{C}$, arrows

757 indicate examples of double labeled cells) compared to GFP- controls (D). Counts of SOX2+ and

758 GFP+ cells were made directly from $\mathrm{Z}$ stack images $(19 \mu \mathrm{m}$ thick, $1 \mu \mathrm{m}$ steps, from $\mathrm{Z}$ stack

759 images using StereoInvestigator software from MBF). The relative proportions of single, and

760 double-labeled cells in the DG were quantified (E), with 71\% of SOX2 positive cells expressing

761 GFP. A majority of DCX+ $(\mathbf{F}, \mathbf{H})$ cells in the DG also express GFP $(\mathbf{G}, \mathbf{H}$, arrows indicate

762 examples of double labeled cells) compared to GFP- controls (I). Counts for DCX+ and GFP+

763 were performed on $10 \mu \mathrm{m}$ thick, $1 \mu \mathrm{M}$ step size, $\mathrm{Z}$ stack images using Image $\mathrm{J}(\mathrm{n}=3)$ of the dentate

764 gyrus. The relative proportions of single, and double-labeled cells in the DG were quantified (J)

765 with $85 \%$ of DCX+ cells expressing GFP. GFAP (Red), NeuN (Blue), and GFP triple

766 immunolabeling was perfused on 1-month old mice. We observed GFAP and GFP colabeling in

767 both the SGZ of the DG (K-N, arrows), as well as in the CA region $(\mathbf{O}-\mathbf{R})$ where most GFAP+

768 cells are present in the stratum oriens or stratum radiatum. NeuN+/GFP+ double positive cells

769 were primarily observed in the stratum pyramidale (SP) of the CA region in the hippocampus

770 (double arrows). These cells were quantified by unbiased stereology with the StereoInvestigator

771 (Table 3). Scale bar in $\mathbf{I}$ is $25 \mu \mathrm{m}$ for images A-D and F-I, Scale bar in $\mathbf{R}$ is $50 \mu \mathrm{m}$ for images $\mathbf{K}$ -

772 R. Arrows indicate examples of double labeled cells. 

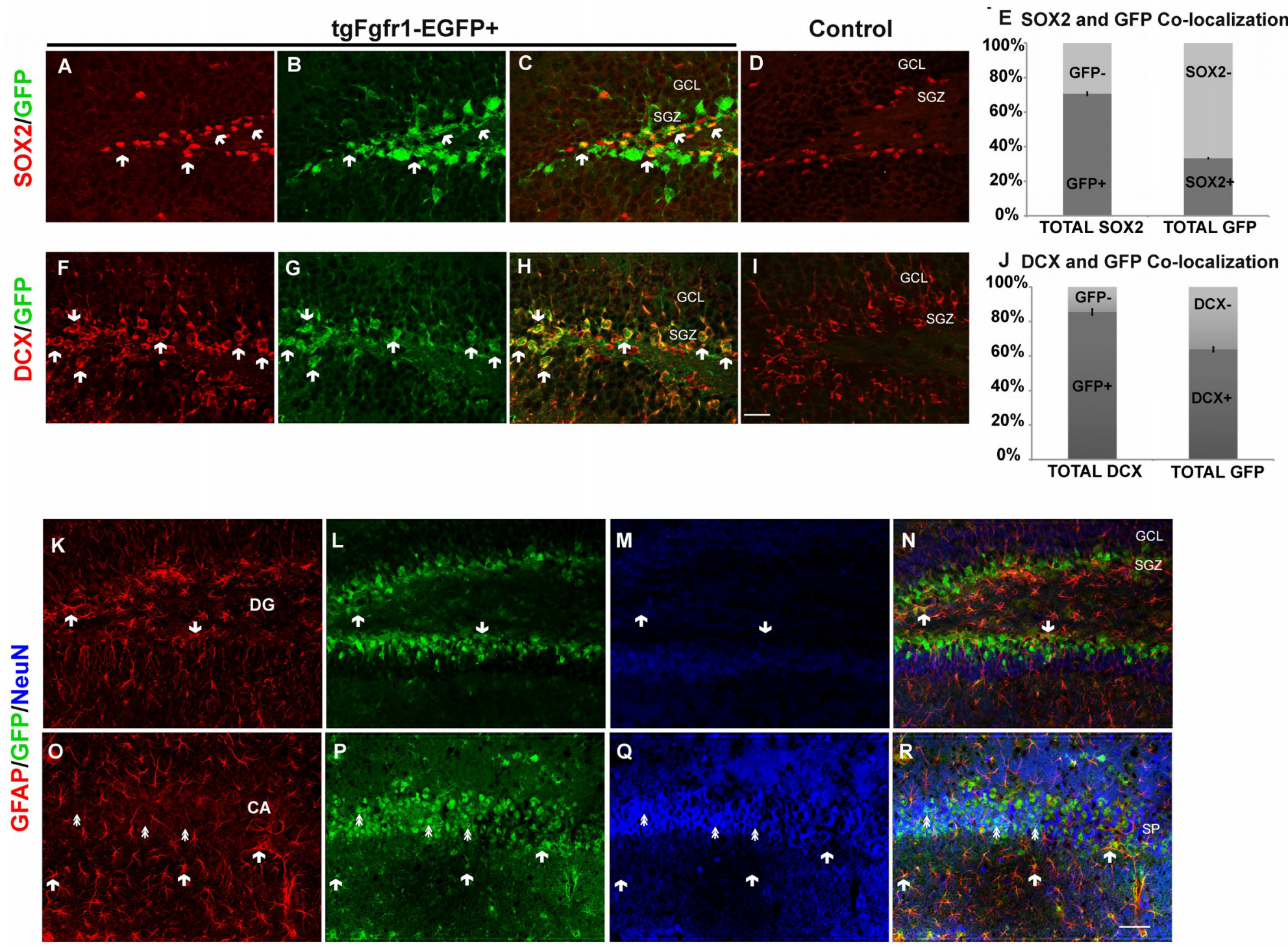
773 Figure 6. Fgfr1 expression in the SVZ and rostral migratory stream of 1-month mice. GFP

774 (A,E,D,H), GFAP (B,F,G,H), NeuN (C,D), immunostaining of the SVZ in 1- month tgfgfrl-

$775 E G F P+$ mice $(\mathbf{A}-\mathbf{H}, \mathrm{n}=3) . \mathrm{GFP}+$ cells of the SVZ colocalized with GFAP + cells $(\mathbf{D}$, and $\mathbf{G}, \mathbf{H}$.

776 Arrowheads in $\mathbf{E}-\mathbf{H}=$ GFAP/GFP+ cells and GFAP+ fibers. GFP $(\mathbf{I}, \mathbf{K}, \mathbf{L})$ and SOX2 $(\mathbf{J}, \mathbf{K}, \mathbf{L})$

777 staining demonstrated that many, but not all SOX2 + cells also colabel with GFP $+(\mathbf{K}$ and $\mathbf{L}$,

778 arrows indicate double labeled cells, DAPI staining included in L). In contrast, DCX+

779 neuroblasts in the SVZ and rostral migratory stream (RMS) did not colabel with GFP (M-P).

780 Scale bar is $50 \mu \mathrm{m}$ in A-D and M-P and $25 \mu \mathrm{m}$ in E-L. dashed lines indicated SVZ region 781 examined. 


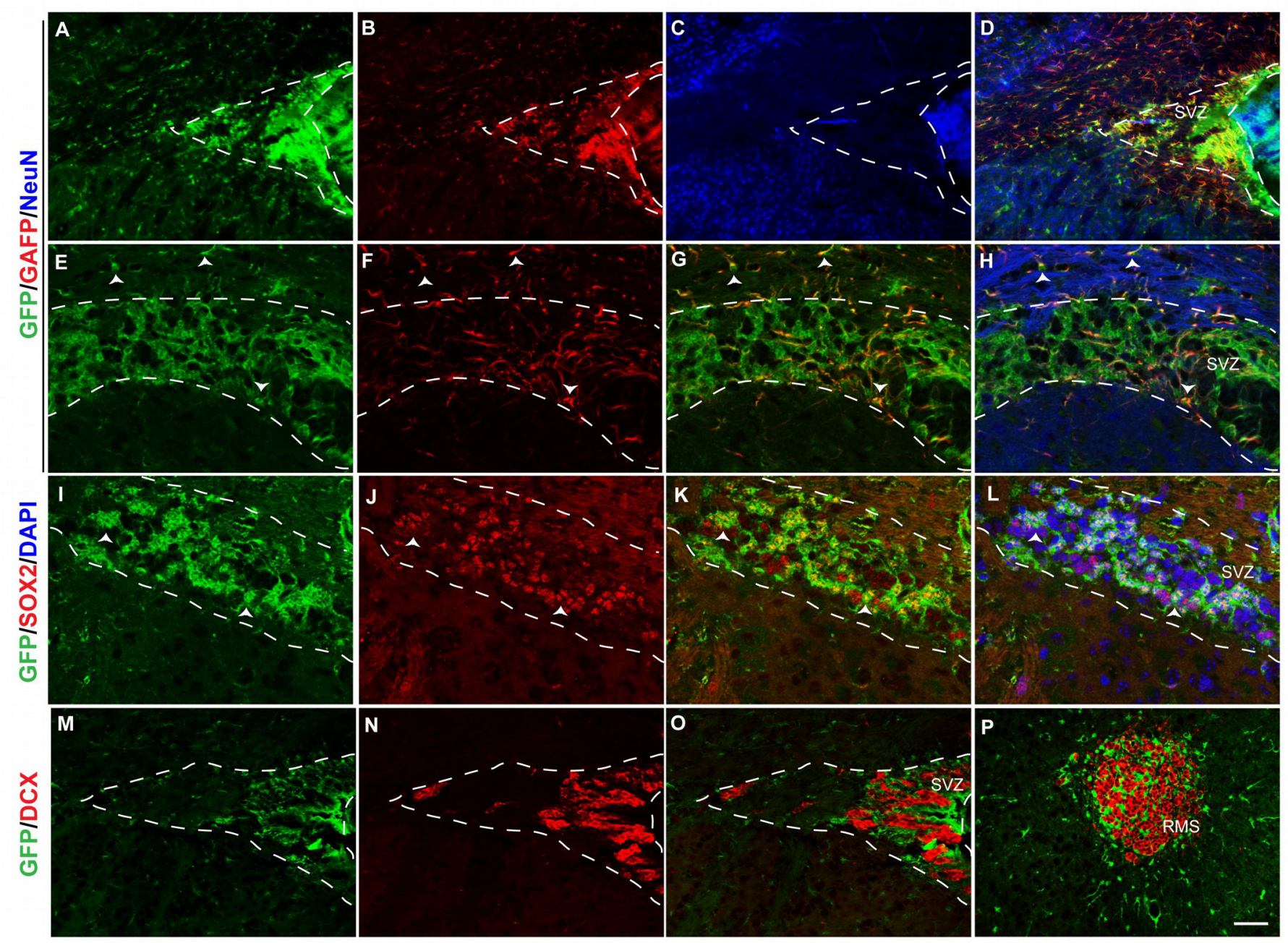


782 Figure 7. Fgfr1 expression in the cortex of 1-month mice. Cortical GFAP (Red), NeuN (Blue),

783 and GFP immunostaining in one-month $\operatorname{tg} f g f r l-E G F P+$ mice $(\mathbf{A}-\mathbf{E}, \mathrm{n}=3)$ and control $\operatorname{tg} f g f r l$ -

$784 E G F$ - mice $(\mathbf{F}, \mathrm{n}=3)$. GFP+ cells colocalized with GFAP+ (arrows) (A, B, merged in $\mathbf{D}$, low

785 magnification in $\mathbf{E}$ ), and some $\mathrm{NeuN}+$ (double arrows) (B, C, merged in $\mathbf{D}$, lower magnification

786 in $\mathbf{E})$. Immunostaining for Olig2 + in $\operatorname{tg} f g f r l-E G F P+\operatorname{mice}(\mathbf{G}, \mathbf{H}, \mathrm{Red}=\mathrm{Olig} 2$, Blue=DAPI $)$

787 compared to tgfgfrl-EGF- mice (I) demonstrated that many Olig2+ cells colocalized with GFP.

788 DAPI staining omitted from low magnification pictures in $\mathbf{G}$ and $\mathbf{I}$. Scale bars are $50 \mu \mathrm{m}$. Dashed

789 line denotes top of cortex. 
tgFgfr1-EGFP

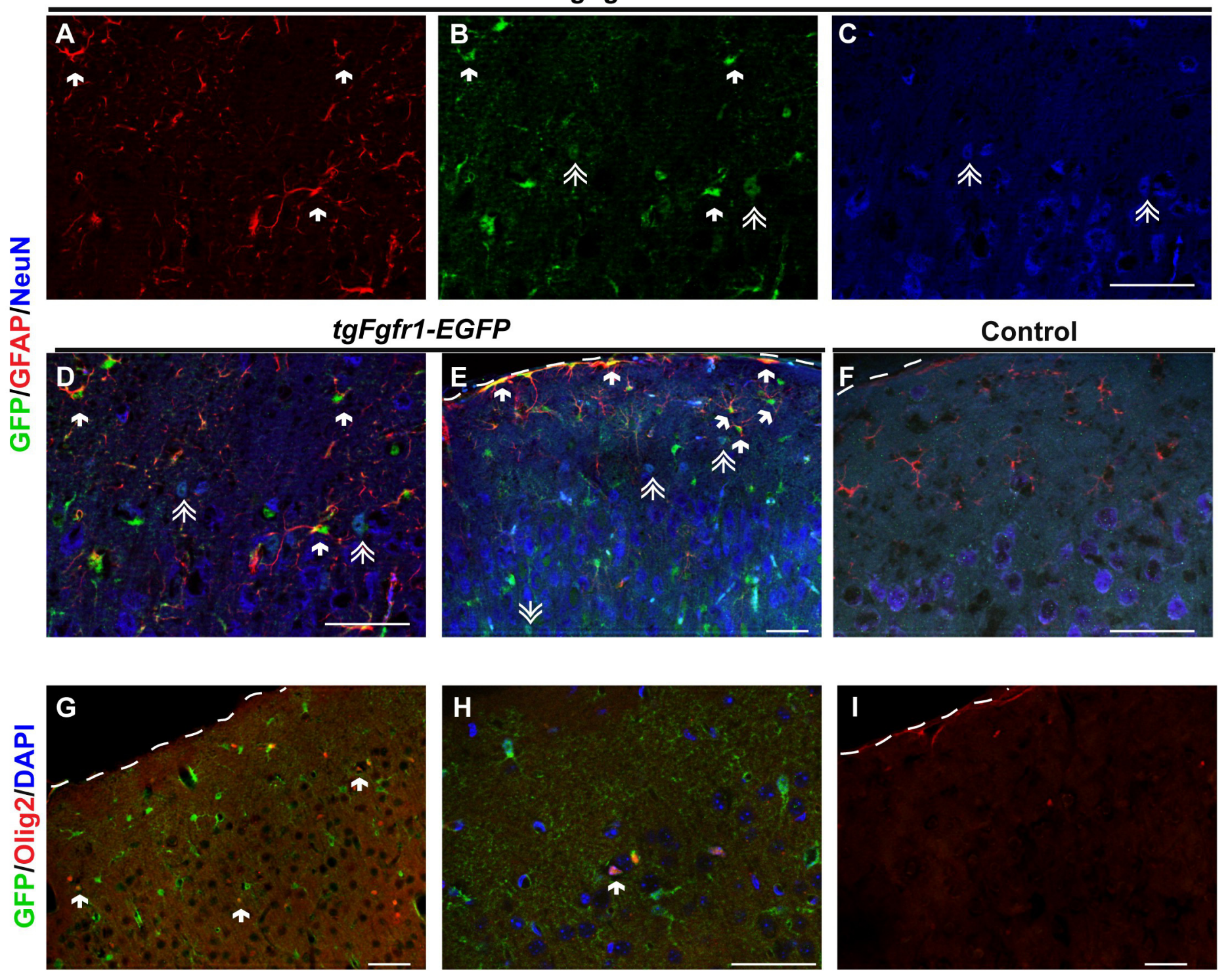


790 Figure 8. Fgfr1 expression in the hypothalamus. SOX2+ positive cells were observed along

791 the third ventricle of $\operatorname{tg} f g f r 1-E G F$ - control mice (A-C) and $\operatorname{tg} f g f r l-E G F+$ mice (D- I). These

792 SOX2 + cells also express GFP under the Fgfr1 promoter (D-I). GFAP+ tanycytes along the third

793 ventricle and arcuate nucleus also colocalize with GFP, as do GFAP+ cells within the

794 hypothalamus (J-L). NeuN+ cells in the hypothalamus do not colocalize with GFP (M-O). A-L,

7951 month; M-O, P7. Scale bar is $50 \mu \mathrm{m} .3 \mathrm{~V}=$ Third Ventricle, ME= Median Eminence, Arc=

796 Arcuate Nucleus. 


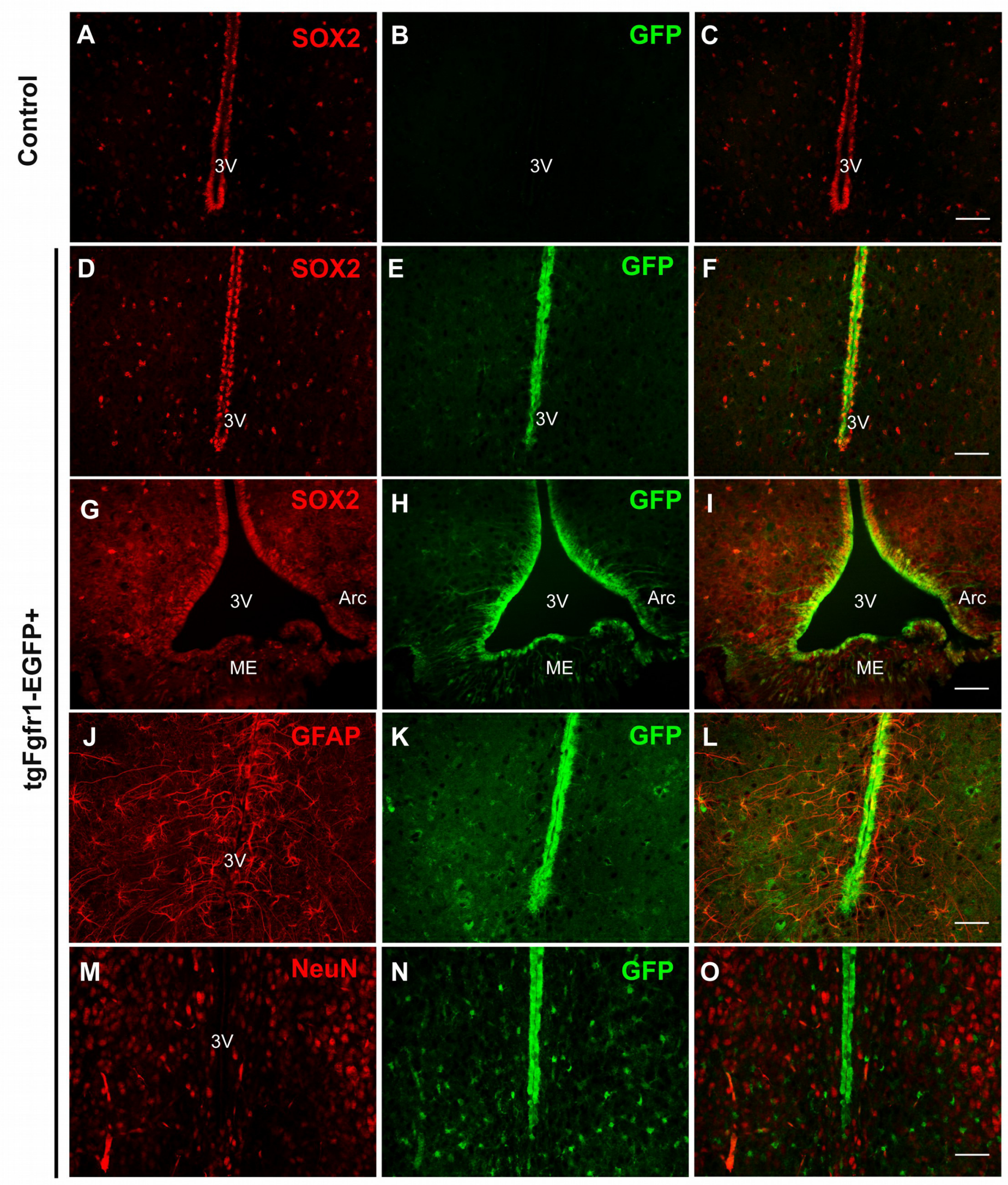


797 Figure 9. Fgfr1 expression in the 1-month interneurons. GAD67, CR, SST, and GFP

798 immunostaining of the cortex, DG, and SVZ in one-month old tgfgfrl-EGFP-controls (A, E, I,

$799 \mathrm{n}=2$ SST, n=3 GAD67, CR) and tgfgfr $1-E G F P+$ mice (B-D, F-H, J, K, n=2 SST, n=3 GAD67,

800 CR). GFP+ cells colocalized with GAD67+ cells in the cortex (B, arrows), but not in the DG (C)

801 and SVZ (D). Some CR+ cells express GFP in the cortex (F), DG (G) and SVZ (H). Some SST+

802 cells express GFP in the anterior cingulate of the cortex $(\mathbf{J})$, but not in the DG $(\mathbf{K})$. Scale bars are

$80350 \mu \mathrm{m}$. Dashed lines indicate $\mathrm{SVZ}, \mathrm{AC}=$ anterior cingulate, $\mathrm{DG}=$ dentate gyrus, SVZ. Arrows

804 denote double labeled cells.

Control
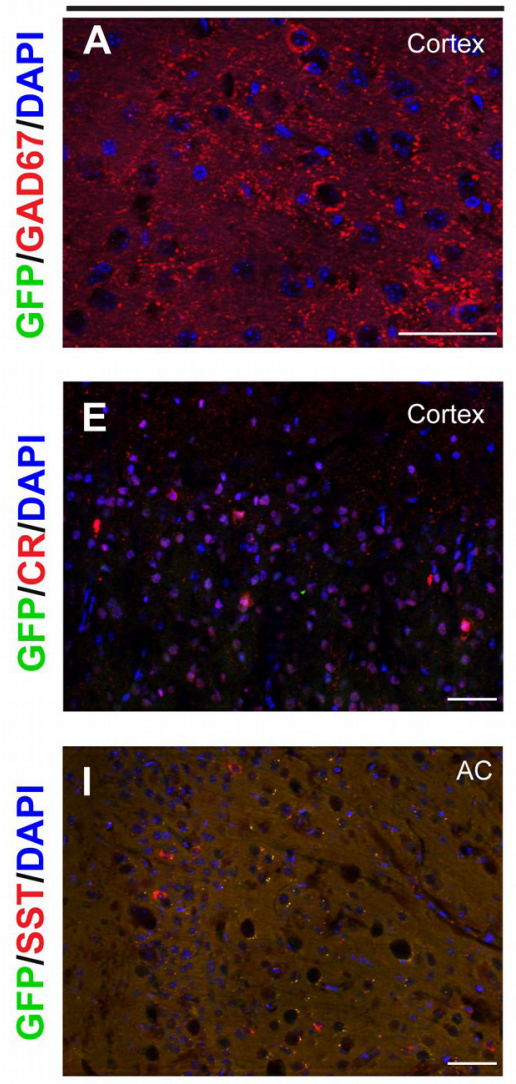

$\operatorname{tgFgfr1-EGFP+~}$
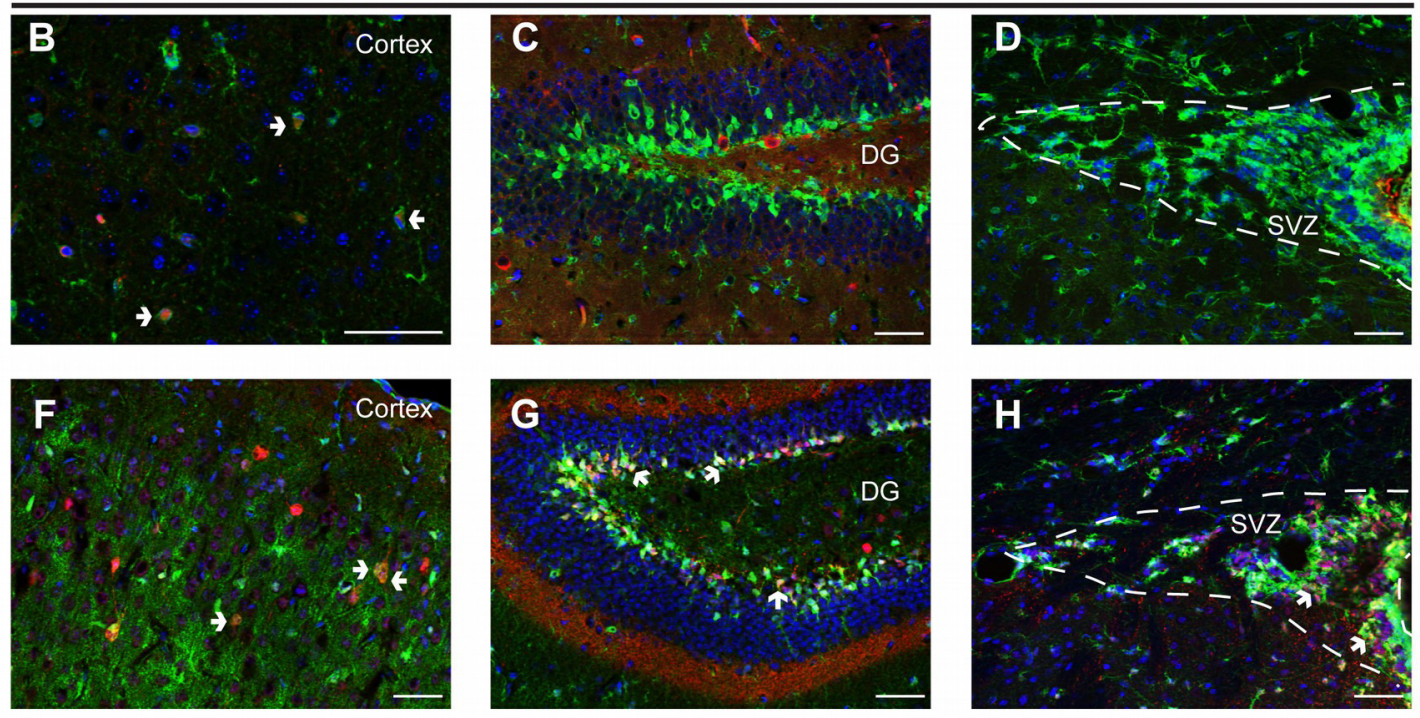

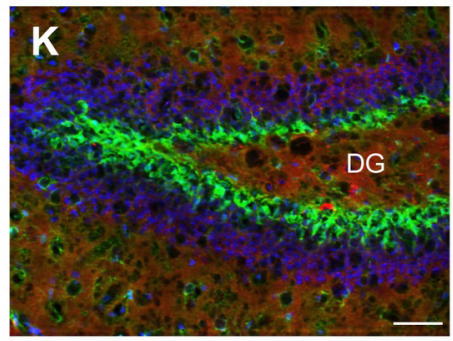

